\title{
Methods for Determining Radionuclide Retardation Factors: Status Report
}
J. F. Relyea
R. J. Serne
D. Rai

April 1980

Prepared for the U.S. Department of Energy under Contract DE-AC06-76RLO 1830

Pacific Northwest Laboratory Operated for the U.S. Department of Energy by Battelle Memorial Institute 
NOTICE

This report was prepared as an account of work sponsored by the United States Government. Neither the United States nor the Department of Energy, nor any of their employees, nor any of their contractors, subcontractors, or their employees, makes any warranty, express or implied, or assumes any legal liability or responsibility for the accuracy, completeness or usefulness of any information, apparatus, product or process disclosed, or represents that its use would not infringe privately owned rights.

The views, opinions and conclusions contained in this report are those of the contractor and do not necessarily represent those of the United States Government or the United States Department of Energy.

\author{
PACIFIC NORTHWEST LABORATORY \\ operated by \\ BATTELLE \\ for the \\ UNITED STATES DEPARTMENT OF ENERGY \\ Under Contract DE-AC06-76RLO 1830
}
Printed in the United States of America Available from
National Technical Information Service United States Department of Commerce 5285 Port Royal Road
Springfield, Virginia 22151

Price: Printed Copy s $\therefore$ Microfiche $\$ 3.00$

NTIS

•Pages Selling Price

\title{
001-025
}

026.050

051-075

076-100

$101-125$

126-150

$151-175$

176-200

201.225

226-250

251-275

$\$ 4.00$

$\$ 4.50$

$\$ 5.25$

$\$ 6.00$

$\$ 6.50$

$\$ 7.25$

$\$ 8.00$

$\$ 9.00$

$\$ 9.25$

$\$ 9.50$

$\$ 10.75$

$276-300+\$ 11.00$ 
METHODS FOR DETERMINING RADIONUCLIDE

RETARDATION FACTORS: STATUS REPORT

\author{
J. F. Relyea \\ R. J. Serne \\ D. Rai
}

Apri1 1980

Prepared for

the U.S. Department of Energy

under Contract DE-AC06-76RLO 1830

Pac if ic Northwest Laboratory

Richland, Washington 99352 


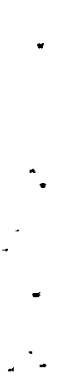




\section{EXECUTIVE SUMMARY}

This report identifies a number of mechanisms that retard radionuclide migration, and describes the static and dynamic methods that are used to study such retardation phenomena. Both static and dynamic methods are needed for reliable safety asessments of underground nuclear-waste repositories. This report also evaluates the extent to which the two methods may be used to diagnose radionuclide migration through various types of geologic media, among them unconsolidated, crushed, intact, and fractured rocks.

Adsorption is one mechanism that can control radionuclide concentrations in solution and therefore impede radionuclide migration. The terms sorption and adsorption are often used to describe the process by which radionuclides are removed from solution by a solid phase. The terms are usually interpreted as applying to a reversible ion exchange or surface adsorption reaction that can be described by a sorption isotherm. Other mechanisms that control a solution's radionuclide concentration and radionuclide migration are precipitation of hydroxides and oxides, oxidation-reduction reactions, and the formation of minerals that might include the radionuclide as a structural element.

The retardation mechanisms mentioned above are controlled by such factors as surface area, cation exchange capacity, solution pH, chemical composition of the rock and of the solution, oxidation-reduction potential, and radionuclide concentration.

The rock and ground water used for nuclide migration/retardation studies should be fully characterized before the start of the investigation, so that an a priori assessment of the important retardation mechanisms can be made. Rocks and ground waters used in determining retardation factors should represent the expected equilibrium conditions in the geologic system under investigation.

Static test methods can be used to rapidly screen the effects of the factors mentioned above. This method can then be used to gather data on the factors as they affect the retardation of a radionuclide in a given rock and 
ground-water system. Dynamic (or column) testing, on the other hand, is needed to assess the effects of hydrodynamics and the interaction of hydrodynamics with the other important parameters. Because dynamic tests are more time consuming, expensive, and space-demanding than static tests, dynamic testing will be used to confirm the predictions generated by static tests.

This paper proposes both a standard method for conducting batch Kd determinations (Appendix $A$ ), and a standard format for organizing and reporting data (Appendix B). Dynamic testing methods are not presently developed to the point that a standard methodology can be proposed. Appendix $C$ outlines normal procedures for column experimentation and identifies the data that are needed to analyze a column experiment. 


\section{ACKNOWLEDGMENTS}

This work was supported by the Waste/Rock Interaction Technology (WRIT) Program being conducted by Pacific Northwest Laboratory. The program is sponsored by the Office of Nuclear Waste Isolation which is managed by Battelle Memorial Institute under Contract DE-AC06-76RLO 1830 with the Department of Energy.

The ideas and suggestions of Dr. Norman Hubbard (ONWI) are greatly appreciated.

The experimental efforts of many researchers have been reviewed and incorporated into this paper. Appreciation is expressed to the principle investigators below and to the many others involved in the ir projects:

$\begin{array}{ll}\text { Dr. G. Scott Barney } & \begin{array}{l}\text { Rockwell Hanford Operations, } \\ \text { Richland, Washington }\end{array} \\ \text { Dr. Chet W. Francis } & \text { Oak Ridge National Laboratory, } \\ \text { Oak Ridge, Tennessee } & \text { Lawrence Livermore Laboratory, } \\ \text { Mr. Daniel G. Coles } & \text { Los Alamos Scientific Laboratory, } \\ \text { Dr. Bruce R. Erdal } & \text { Los Alamos, New Mexico } \\ \text { Dr. Geoffrey G. Eichnolz } & \begin{array}{l}\text { Georgia Institute of Technology, } \\ \text { Atlanta, Georgia }\end{array} \\ \text { Dr. Robert E. Meyer } & \text { Oak Ridge National Laboratory, } \\ & \text { Oak Ridge, Tennessee } \\ \text { Dr. Martrin G. Seitz } & \text { Argonne National Laboratory, } \\ & \text { Argonne, Illinois } \\ \text { Dr. Robert J. Silva } & \text { Lawrence Berkeley Laboratory, } \\ & \text { Berkeley, California }\end{array}$





\section{CONTENTS}

EXECUTIVE SUMMARY

ACKNOWLEDGMENTS

INTRODUCTION

FACTORS AFFECTING RETARDATION OF RADIONUCLIDE MIGRATION . $~ 2$

Surface Area and CEC $\quad . \quad \cdot \quad \cdot \quad \cdot \quad \cdot \quad \cdot \quad \cdot \quad \cdot 3$

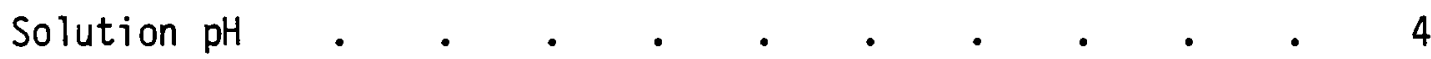

Temperature $\quad$ • $\quad$ •

Chemical Composition .

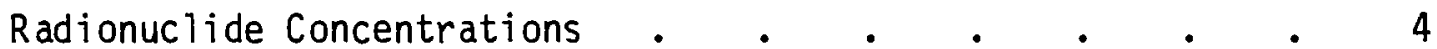

Particulate Migration $\quad$. $\quad . \quad$. $\quad$. $\quad$. $\quad$. 5

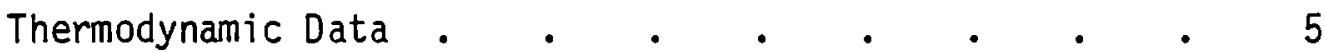

CONCLUSIONS

RECOMMENDATIONS

AVAILABLE METHODS $• \quad \cdot \quad \cdot \quad \cdot \quad \cdot \quad \cdot \quad \cdot \quad \cdot \quad \cdot \quad \cdot \quad \cdot 13$

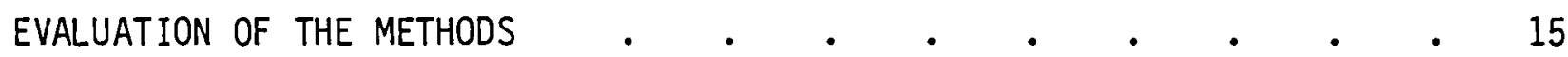

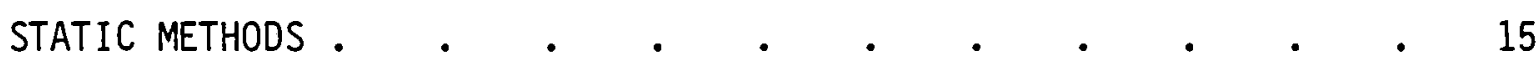

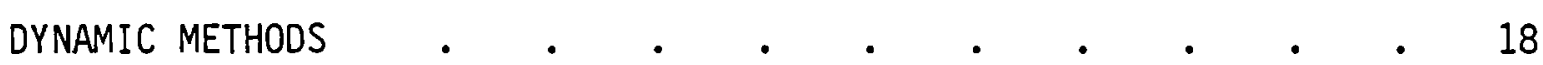

REFERENCES .

APPENDIX A: PROPOSED STANDARD BATCH Kd PROCEDURE . . . . . . . A-1

APPENDIX B: REPORTING RESULTS FROM RADIONUCLIDE MIGRATION
EXPERIMENTS.

APPENDIX C: COLUMN PROCEDURES AND DATA REPORTING . . . . . . C-1 



\section{INTRODUCTION}

Saf ety-assessment transport models that consider radionuclide retardation are based on the assumption that radionuclide sorption obeys ideal chromatographic theory. In accordance with this theory, the transport modellers assume that: 1) sorption of a radionuclide is reversible, and 2) radionuclide movement is retarded relative to the ground water. To predict the movement of a radionuclide we must know the bulk density and porosity of the rocks through which the water flows, and we must determine a distribution coefficient that describes the partitioning for each radionuclide between the solution and solid phases.

The distribution coefficient, $K d$, is defined as the ratio of the equilibrium radionuclide concentration on the solid phase $(\mu \mathrm{g} / \mathrm{g})$ to the equilibrium concentration of the radionuclide $(\mu \mathrm{g} / \mathrm{m} 1)$ when it was initially in solution. The $\mathrm{Kd}$ is dependent upon and therefore reflects--in combination--a particular radionuclide, rock, ground-water composition, and temperature. If any one of these parameters is changed, the Kd is likely to vary. A high Kd value results in low radionuclide migration velocities relative to ground water velocities. Because Kd values may vary with the type of rock and its associated ground water composition (Erdal et a1. 1977, 1978, 1979; Meyer 1977, et a1. 1978, et a1. 1979; Relyea et a1. 1977, 1978, 1979a; Seitz et al. 1979), conservatively low values are often used to insure that predicted migration rates are higher than one would realistically expect. This procedure places a lower limit on the time required for radionuclide migration from a repository to the biosphere.

To date, the $K d$ approach to quantification of radionuclide retardation has been an empirical one. This approach makes no distinctions among the many mechan isms that control radionuclide concentrations in ground water, nor does it account for other mechanisms that might control radionuclide concentrations, such as precipitation. Recent work in plutonium solution chemistry (Rai 1977) has shown that $\mathrm{Pu}$ solution concentrations are limited by the precipitation of $\mathrm{PuO}_{2}$ and $\mathrm{Pu}(\mathrm{OH})_{4}$ in natural waters and under expected repository conditions. Concentrations of radionuclides other than Pu may also be controlled by 
precipitation of hydroxides and oxides or by the formation of other mineral phases that include the radionuclides as structural elements. When precipitation is a factor, the use of distribution coefficients in the usual manner can be misleading.

In addition to being affected by precipitation, the concentration of an element in solution may be controlled by the element's reaction with natural minerals, which results in the formation of new, stable phases that incorporate the radionuclide. If experiments are more carefully designed to obtain data on these mechanisms, comprehensive models of radionuclide behavior will be possible. A transport model that considers mineral formation/precipitation and detailed sorption/desorption reactions will yield realistic and scientifically defensible limits on radionuclide migration. As these new data are acquired, they will be incorporated to improve the established methods for experimentally determining retardation factors.

The scientific community must develop a measurement method that relates laboratory sorption/desorption and retardation data for crushed or intact material to the deep geologic environment (500 to $2000 \mathrm{~m}$ ). Methods for field testing must also be developed. Comparing field data with data obtained from laboratory experiments will generate appropriate transformation or scaling factors and provide more confident predictions about radionuclide retardation during the release of radionuclides from a repository to the surrounding rock and ground-water system.

The objectives of this paper are: 1) to describe the factors that affect retardation of radionuclide migration in ground-water and rock systems; 2) to describe the methods used to study nuclide retardation mechanisms (such as sorption/desorption and precipitation); and 3) to evaluate the experimental procedures or tests (static and dynamic) presently used to determine the retardation of radionuclides by a geologic system.

\section{FACTORS AFFECTING RETARDATION OF RADIONUCLIDE MIGRATION}

Efforts to obtain radionuclide distribution coefficients $(K d)$ have been extensive (Serne 1977, 1978) and have sometimes been hampered by a lack of 
knowledge about the chemical behavior of the element being studied. Adsorption of many radionuclides has been studied under a wide variety of environmental conditions. The studies reported in this paper were conducted to supply empirical Kd values for certain safety assessment models. Because of the lack of information about sorption mechanisms, few of the empirical Kd values could be extrapolated to conditions different from those used to determine a particular Kd. Radionuclide concentrations were sometimes too high: the measured Kd values reflected precipitation reactions, not sorption. Elements having multiple oxidation states have sometimes shown wide variation in measured $\mathrm{Kd}$ values because of a lack of control of the oxidation-reduction potential.

At present, sorption/desorption, precipitation, and oxidation/reduction reactions are indistinguishable from one another in a single batch Kd experiment. The need for retardation mechanism studies clearly exists. We must insure that $\mathrm{Kd}$ measurements are valid for the conditions under which the Kd's are measured.

Regardless of the type of retardation experiment being carried out, the parameters that affect radionuclide migration must be at least qualitatively understood. Many factors affecting both reversible and non-reversible sorption/desorption reactions also affect mineral formation and precipitation of radionuclide hydroxides and oxides. Some of the most important parameters include: $\mathrm{pH}$; temperature; chemical composition of the solids and solutions; ionic strength; particle size; adsorption on suspended particles; radionuclide concentration; concentration of complexing ligands; oxidation-reduction potential; surface area; and cation exchange capacity (CEC).

Surface Area and CEC

Surface area and cation exchange capacity (CEC) primarily affect sorption/desorption reactions on secondary minerals found in rocks and aquifers. The $\mathrm{Kd}$ of a radionuclide adsorbed by an ion exchange mechanism increases with an increase in the cation (or anion) exchange capacity. Mineral dissolution/ formation and precipitation reactions, however, may change both the CEC and surface area over long periods of time, thereby affecting the reversible, nonselective sorption/desorption capacity. 
Solution $\mathrm{pH}$

Solution $\mathrm{pH}$ affects both mineral stability and the solubility of the solid phases of radionuclides. Hydrolys is results in both cation-hydroxyl complexation and a general reduction of effective cationic charge to the extent that cation hydrolys is can form an anion. Hydrolysis, obviously, is also controlled by $\mathrm{pH}$. In order to predict radionuclide behavior, the $\mathrm{pH}$ and hydrolys is constants of the nuclide/ground-water/and rock system must be known.

\section{Temperature}

Temperature increases generally cause reaction rates to increase, insofar as higher temperatures lower the stabilities of some minerals and thereby speed their dissolution. Some minerals, on the other hand, become more stable at higher temperatures. Whatever the direction of the change in stability, the suite of minerals expected in a particular environment may become altered as changes in temperature occur.

\section{Chemical Composition}

The chemical composition of both ground water and rocks directly affects the sorption of radionuclides and the stability of minerals present in the geologic environment. Simultaneously occurring chemical reactions control such things as the chemical composition of solid surfaces and solutions, a solution's ionic strength, a solution's oxidation-reduction potential, and the nuclides' propensity for complex formation. Attempts to realistically describe actual systems by using equilibrium thermodynamic-geochemical models have been limited by a lack of thermodynamic and kinetic data on many solid phases and solution species. A safety analysis of geochemical systems requires information about site-specific solid and solution chemical composition, mineralogy, $\mathrm{pH}$, redox potential, and the like.

Radionuclide Concentrations

Radionuclide concentrations in ground water may be controlled by such factors as 1) the stability of the waste form; 2) the forming of precipitates at lower temperatures outside the repository; 3 ) the solubilities of minerals which contain the radionuclide; and 4) sorption/desorption reactions. Kd 
values usually decrease with increasing nuclide concentrations above trace levels because of competition between similar radionuclides for sorption sites. This competition for sites is similar in nature to the reduction in Kd that results when the concentration of competing cations increases. If no compensation is made for solubility constraints, experiments involving relatively insoluble nuclides at high concentration often will yield erronously high $\mathrm{Kd}$ values. High radionuclide concentrations are of ten used to facilitate easy detection. It is often assumed that any decrease in radionuclide solution concentration is caused by adsorption on a solid surface. Since many radioactive waste elements form insoluble hydroxides at environmental $\mathrm{pH}$ values (neutral to slightly basic), the use of high initial radionuclide concentrations could result in precipitation of the nuclide and, consequently, in lowered solution concentration. These experimental conditions (low solubility, high initial nuclide concentration, and neutral or higher pH values) yield invalid Kd values, because radionuclide concentrations could be a function of the solubility of the precipitate (hydroxide, oxides) instead of the result of reversible sorption/desorption reactions.

\section{Particulate Migration}

Particulate migration may be responsible for transport of radionuclides if the radionulcides are adsorbed by the particulates. If the particles are larger than the pores through which the ground water moves, the particles will be filtered out of the ground water. Smaller particles may also be either filtered or adsorbed on larger surfaces or both. Particle migration is most likely to be a problem in fracture flow where contact between the particulates and wall surfaces is much less than in flow through porous media.

\section{Thermodynamic Data}

Thermodynamic data for reactions involving man-made radionuclides are much less abundant than data for natural elements in geochemical reactions. Many of the available data for radionuclides were determined in highly acidic, high-ionic-strength systems and cannot be readily extrapolated to geochemical systems or to safety assessments of site-specific repositories. 


\section{CONCLUSIONS}

Distribution coefficients used for safety assessments should be determined with materials that represent the expected equilibrium between rocks (porous or fractured) and ground water. Although static tests are generally valid for loose sediments or poorly-consolidated aquifer materials, the results from these tests should be compared periodically with results from dynamic tests.

Crushed materials can be used to rapidly screen the combined effects of variables such as temperature, radionuclide concentration, $\mathrm{pH}$, Eh and ranges of ground-water composition. The possibility exists that equilibrium may not be established between crushed rock and ground water, because crushed rock presents new, fresh surfaces, which are absent in an intact aquifer sample.

When conducting a radionuclide migration experiment, the radionuclide concentrations of the ground water must be at levels that preclude precipitation. If the solubility of a radionuclide is unknown under the desired experimental conditions, it should be determined before proceeding with retardation experiments.

Flow rate, temperature, and preparation of rock samples influence the results obtained from dynamic studies. Dynamic studies must be conducted under conditions that simulate the in situ (or expected in situ) conditions for the particular geologic-hydrologic region under investigation. 



\section{RECOMMENDATIONS}

To obtain radionuclide retardation data for safety assessment of a nuclear waste repository, several logical steps must be followed:

A. The rocks and ground water must be characterized by means of onsite investigation.

1. Rock Samples. At a minimum, the mineralogy should be determined by optical and $X$-ray diffraction techniques to ensure that samples used for retardation measurements are representative of the most likely proposed repository-to-biosphere transport paths (aquifers).

a. Mineralogical analysis should identify and determine the proportion of each of the primary and secondary minerals present. The overall chemical composition should also be determined. Samples should be free of contamination from lubricants used in the drilling process. Coating on individual particles (unconsolidated sediments) or pore surfaces by precipitates of iron, aluminum, silicon, and organic matter should be reported.

b. Surface area and cation exchange capacity should be determined. Porosity and permeability should be determined for comparison with field measurements.

c. Analysis of the whole rock for major elements should include a search for: $\mathrm{SiO}_{2}, \mathrm{Al}_{2} \mathrm{O}_{3}, \mathrm{TiO}_{2}, \mathrm{FeO}, \mathrm{Fe}_{2} \mathrm{O}_{3}, \mathrm{MnO}$, $\mathrm{CaO}, \mathrm{MgO}, \mathrm{K}_{2} \mathrm{O}, \mathrm{Na}_{2} \mathrm{O}$, and $\mathrm{P}_{2} \mathrm{O}_{5}$.

d. Trace element determination should include: $B a, C S, F$, $\mathrm{La}, \mathrm{Li}, \mathrm{Pb}, \mathrm{Ra}-\mathrm{Rn}, \mathrm{Rb}, \mathrm{S}, \mathrm{Se}, \mathrm{Sr}, \mathrm{U}$, and $\mathrm{Zr}$.

2. Ground water from each aquifer should be characterized individually. 
a. Field measurements should be made of $\mathrm{pH}, \mathrm{Eh}, \mathrm{Fe}^{+2} / \mathrm{Fe}^{+3}$ $\mathrm{SO}^{-2} / \mathrm{S}^{-2}$ and dissolved oxygen. An in situ sample should be taken for determination of dissolved gases: $\mathrm{CO}_{2}, \mathrm{H}_{2} \mathrm{~S}, \mathrm{CH}_{4}$ and $\mathrm{O}_{2}$.

b. Laboratory analysis of major ground-water constituents should include $\mathrm{Na}^{+}, \mathrm{K}^{+}, \mathrm{Mg}^{+2}, \mathrm{Ca}^{+2}, \mathrm{Cl}^{-}, \mathrm{HCO}_{3}^{-}, \mathrm{CO}_{3}=$, $\mathrm{NO}_{3}{ }^{-}, \mathrm{NO}_{2}$ and $\mathrm{SO}_{4}=$

c. Trace element analysis should include, $\mathrm{Cs}^{+}, \mathrm{Fe}^{+2}, \mathrm{Fe}^{+3}$, $\mathrm{Sr}^{+2}, \mathrm{Si}, \mathrm{Mn}, \mathrm{I}, \mathrm{Ba}^{2+}, \mathrm{Rb}^{+}, \mathrm{Br}^{-}, \mathrm{B}, \mathrm{PO}^{-3}, \mathrm{~S}^{2-}$, and soluble organic carbon.

B. Available thermodynamic data and geochemical models should be used to determine whether ground water and aquifer material have established equilibrium. Thermodynamic data should also be used whenever possible to predict maximum radionuclide concentrations in the ground water.

C. Experimental determinations should be made for radionuclide solubilities that cannot be predicted from thermodynamic data. Solubilities should be studied over the range of ground waters observed at a site and for any ground-water type that may exist after a repository breach.

D. Static studies should be conducted with site-specific rock samples and ground-water compositions. Experimental temperatures should be the same as those found in the aquifer being investigated. The laboratory system should be as close to equilibrium as possible before the rocks are allowed to come in contact with the spiked ground water. Static studies will investigate the effects of $\mathrm{pH}$, Eh, temperature, type of aquifer material, radionuclide concentration, and ground-water composition over the range of observed or expected field conditions.

E. We realize that static tests do not represent the hydrodynamics of a geologic disposal system. However, the alternative method (dynamic 
testing), which does take hydrodynamics into account, is impractical for fully investigating all the important retardation parameters, because dynamic testing is costly, time consuming, and requires more equipment and laboratory space than static testing. Dynamic methods will be used to verify predictions made by static tests in critical areas and to investigate hydrodynamic interactions between geologic systems and waste radionuclides. Outlines of standard procedures for batch $\mathrm{Kd}$ determinations and data reporting are included as appendices to this report. A future report will address standardization of dynamic retardation tests. At present, dynamic retardation methods need futher evaluation to resolve anomolous results and to gain experience with intact, porous, and fracture-flow cores. 



\section{AVAILABLE METHODS}

Two types of methods--the static or "batch" technique and the dynamic or "column" method--are presently used for Kd determinations and can be used for the study of sorption/desorption mechanisms, precipitation, and mineral formation.

The static method utilizes a suspension of crushed rock in ground water that has been spiked with one or more radionuclides. Continuous agitation of the suspension is maintained during the reaction period prior to sampling and analys is. Minimal space, equipment and funds are required, making the static method most expedient when a large number of radionuclides, rocks and minerals, and ground waters are investigated (Relyea 1979d). Sorption parameters such as $\mathrm{pH}$ and chemical composition of solutions may be readily monitored or controlled to determine the approach to equilibrium. Sorption and desorption can be determined as functions of time (for reversibility) and as functions of mass or surface area.

Dynamic methods monitor a tracer solution as it flows through a column of crushed or intact rock. Dynamic experiments include low-pressure, flow-through column studies, which allow observation of nuclide migration in porous rock without sample alteration caused by grinding as in batch experiments. Reversibility, multiple-oxidation states (oxidation-reduction speciation), and physical transport of colloids can be studied with realistic solid-to-solution ratios for porous flow, fracture flow, and flow through crushed rock.

Studies with high-pressure flow through columns containing intact core samples provide better data for flow through fractured and low-permeability rocks than do static methods or columns packed with crushed material.

Axial filtration (Triolo, Harrison and Kraus 1979) is a dynamic method that uses a flow-through, stirred-reactor technique. Advantages are similar to those afforded by classical column techniques, except that low-permeable materials, such as clay (which is not suitable for other dynamic methods), can be studied. 
The static and dynamic methods used for studying the interaction of radionuclides with rock and ground water are complementary. Static methods are especially effective for the study of a wide variety of radionuclide/ ground-water/and rock or soil systems. 


\section{EVALUATION OF THE METHODS}

STATIC METHODS

Although the static method is generally advantageous for studying radionuclide behavior in geologic media, the system is not without its drawbacks. Because hydrologic flow effects are not inherent in the design of static methods, the method cannot be used to study the mobility of radionuclides in geologic media. Since static experiments use suspensions of solids in solution, the solution-to-solid ratio is usually high compared to that found in situ. Studying the adsorption of nuclides that are present in multipleoxidation states is difficult because, in most cases, only the total radionuclide concentration is determined, not the concentration of the separate oxidation states. Methods for determining oxidation states in solution are not available for all radionuclides of interest. Methods for determining oxidation states for adsorbed species are even more scarce. However, separate oxidation states may be studied singly in $\mathrm{pH}-\mathrm{Eh} /$ buffered static systems in which one state predominates. Results for separate oxidation states may then be combined to predict nuclide behavior in the environment.

When rocks or minerals are crushed for use in batch-type static tests, the rock's particle size decreases and its surface area is increased. Fresh surfaces produced by crushing are subject to dissolution when exposed to solution. Dissolution of the solid phase during weathering can lead to the precipitation of amorphous colloids of iron and silicon, which may adsorb or incorporate radionclides in their structure. Experimental leaching of basalt under laboratory conditions has shown that the amorphous, glassy phase dissolves slowly, releasing $\mathrm{Fe}$ and $\mathrm{Si}$ into solution (Barney 1979). Concentrations of $\mathrm{Fe}$ and $\mathrm{Si}$ observed in solution were abnormally high, but filtration through $0.01 \mu \mathrm{m}$ membrane filters reduced their concentrations to levels expected for $\mathrm{Fe}$ and $\mathrm{Si}$ that are in equilibrium with their respective amorphous oxides and hydroxides. Radionuclide concentrations were also reduced by filtration, which indicates that colloids had adsorbed or incorporated the radionuclides. The same study also showed changes in solution composition over a 150-day 
period for ground waters that were in continual contact with crushed granite and crushed argillite. However, no colloid formation was detected in these two experiments. Use of the static method with crushed basalt, granite and argillite has shown that obtaining equilibrium between rocks and ground water may require several months or longer. The rocks or aquifer material selected should already be in equilibrium with the ground water used.

When added to ground water, radioactive tracers may be adsorbed on suspended particles or, if tracer concentrations are too high, they may be precipitated as a radiocolloid. Several studies (Erdal 1979, Coles 1979) have shown that filtration of synthetic ground water is necessary both before adding the tracer (to remove dust particles) and before contacting the spiked ground water with geologic material (to remove precipitated tracer). Any sample taken from solid-solution mixtures (effluent) that will be counted to calculate the $\mathrm{Kd}$ should also be filtered to remove colloids formed during the study. Filtration and centrifugation techniques have been shown to be comparable if care is taken during the centrifugation process and if the filters used do not adsorb the tracer (Erdal 1979). Sorption of tracer by the filter will lower the measured tracer concentration in the effluent and result in a calculated $\mathrm{Kd}$ value that is too high. The failure to remove particulates with sorbed tracer during centrifugation results in a high effluent tracer concentration, which yields a low (but conservative) $\mathrm{Kd}$.

The formation of minerals containing radiotracers and hydroxide precipitates during a static sorption study is not always easily detected. Both precipitation and sorption mechanisms remove tracer from solution and result in an apparent increase in the amount of radionuclide adsorbed. These mechanisms become important as the radionuclide concentration approaches a solubility 1 imit for one of the minerals or precipitates. As more radionuclide is added, more of the mineral or precipitate is formed, and the nuclide solution concentration remains constant (assuming that the kinetics are sufficiently rapid). Since sorption Kd values normally decrease with increasing radionuclide concentrations, an apparent increase of $K d$ with increasing initial concentration indicates that a precipitation or mineral formation mechanism may be responsible for the disappearance of tracer from solution. Another indication that 
sorption has become a secondary mechanism is the constant effluent tracer concentration maintained by the solubility limit when excess tracer is added.

Tracer radionuclides such as $\mathrm{Pu}$ and Am may be sorbed by the walls of the sample container, yielding unrealistically high Kd values. To correct for container-wall sorption of tracers, one may use either 1) the blank-corrected method, which assumes that container-wall sorption is the same whether or not rocks are present; 2) direct determination of adsorbed radionuclides by $X$-ray or gamma-ray counting of the rocks; or 3 ) direct determination of activity on the solid phases (for alpha and beta emitters) by wet chemical stripping or solid dissolution.

The assumption that container wall sorption is constant, whether or not rocks are present, has been shown to be invalid; however, mass balance considerations can be used to calculate Kd values without direct determination of activity on the solids (Relyea 1979b).

Direct measurement of adsorbed activity on the solid phase has been used by several groups (Erdal 1978, Relyea 1979c). Problems associated with this method are usually concerned with attenuation of the X-ray or gamma rays by the solid, or with obtaining a mass balance for alpha or beta emitters, or with obtaining a representative sample of the solid for counting. For radionuclides that are significantly sorbed by blank container walls, direct measurement of solid phase activity is more accurate than blank correction. If wall sorption of a blank container is low, the blank corrected method is faster to use, because solid counting samples need not be prepared. If the activity sorbed on blank tube walls is larger than about $10 \%$ of the average blank influent activity, direct counting of activity adsorbed by solid samples should be used.

Static or batch sorption experiments yield more precise results if the change in nuclide solution concentration upon contact with geologic material is neither very small nor very large. If the $K d$ is small, effluent and influent concentrations are nearly the same, and statistical variation between samples may be larger than differences caused by sorption. If the Kd is very large, little activity will be left in solution. The resulting low count 
rates are then subject to error from statistical fluctuation in background and subtle changes in the counting geometry. Batch Kd experiments are best used to measure Kd values between 1.25 and $400 \mathrm{ml} / \mathrm{g}$ (Relyea 1979d), provided one varies the solution-to-solid ratio only over a practical range (4 to 100) and attempts to keep the effluent/influent activity ratio between 0.2 and 0.8 (20 to $80 \%$ sorption of the tracer).

\section{DYNAMIC METHODS}

Dynamic or column methods are used to simulate migration of radionuclides through porous rocks. In the absence of sorption, a nuclide will move with the flowing ground water and be affected only by dispersion. Sorption retards (or delays) radionuclide movement relative to the average water velocity. Mineral formation and precipitation, given adequate reaction time, place upper limits on radionuclide solution concentrations and thus also retard nuclide movement.

Equipment, space, and time requirements are the major constraints on the number of dynamic migration studies that can be run by a researcher. The experimental setup usually requires a reservoir for spiked solution, a pump to deliver solution from the reservoir to the column, an apparatus to physically contain the crushed or intact rock being tested, and a sample collector for the column effluent. Space for this equipment and for safety equipment (when high pressures are involved) must be provided for the duration of the experiment.

Time is a key constraint in performing dynamic experiments. The retardation factor for a particular radionuclide in a given ground-water and porous rock system (assuming ideal chromatographic sorption behavior) is:

$$
R=1+\frac{\rho_{b} K d}{\Sigma}
$$

where $R$ is the retardation factor; $\rho_{b}\left(\mathrm{~g} / \mathrm{cm}^{3}\right)$ and $\Sigma\left(\mathrm{cm}^{3} / \mathrm{cm}^{3}\right)$ are respectively, the bulk density and porosity of the rock; and $\mathrm{Kd}(\mathrm{ml} / \mathrm{g})$ is the distribution ratio of the radionuclide between solid and liquid phases. A Kd 
value of zero yields a retardation factor of unity, which implies that the water velocity and radionculide migration velocity are the same, according to the following equation:

$$
v_{w}=\frac{v_{n}}{R}
$$

where $\mathrm{V}_{\mathrm{w}}=$ average water velocity, and $\mathrm{V}_{\mathrm{n}}=$ average radionuclide velocity in the porous media. For a relatively porous rock $(\Sigma=0.20)$ with a bulk density of $2.0 \mathrm{~g} / \mathrm{cm}^{3}$, the retardation factor is $R=1+10 \mathrm{Kd}$. A Kd value of $10 \mathrm{ml} / \mathrm{g}$ would give $R=101$, thus, one would not expect the radionuclide to appear in the effluent at significant concentrations until close to 100 pore volumes of ground water had passed through the column. Using a typical column with a length of $5 \mathrm{~cm}$ and a water velocity of $50 \mathrm{~m} / \mathrm{yr}$, approximately 37 days would be required for a $50 \%$ breakthrough. (Effluent concentration is one half that of the influent radionuclide concentration). Similarly, a Kd of $100 \mathrm{ml} / \mathrm{g}$ for another radionuclide or another ground-water and rock combination in the same apparatus (same $\rho_{b}$ and $\Sigma$ ) would require $1 \mathrm{yr}$ for $50 \%$ breakthrough in the laboratory.

When the time required for breakthrough is too long to be practical, the column may be sectioned and the tracer distribution on the rock determined. If chromatographic behavior is obeyed by the tracer, a gaussian peak or error function distribution (depending on the type of tracer injection and the spike or step function) will be observed. The ratio of the distance traveled by the tracer (either the peak or the $50 \%$ maximum loading) to the equivalent distance traveled by the ground water (column length times number of pore volumes passing through the column) gives a direct measurement of the retardation factor. Experiments should be carefully designed to yield useful and accurate data, because equipment and space and time requirements limit the number of dynamic experiments that can be performed.

Several comparisons have been made between $K d$ values found by static (batch) and dynamic (column, axial filtration) methods (Meyer et al. 1977, Coles 1979, Erdal 1979, Gee and Campbell 1980, Seitz 1979). Generally, Kd 
values determined by the batch method are equal to or higher than those from column experiments. In other words, tracer breakthrough in a column may occur earlier than predicted by data from batch sorption measurements.

Meyer et al. (1977) have shown that $\mathrm{Kd}$ values for $\mathrm{Cs}^{+}$on $\mathrm{Na}^{+}$-saturated montmorillonite are the same for batch and column methods using solutions ranging from $0.5 \mathrm{~N}$ to $4.0 \mathrm{~N} \mathrm{NaCl}$. Meyer et al. (1978) have also shown that the batch and column methods produce comparable data for $\mathrm{Sr}$ (II)/Na(I) exchange on a $\mathrm{Na}^{+}$saturated montmorillonite and for $\mathrm{Sr}(\mathrm{II}) / \mathrm{Ca}$ (II) exchange on a $\mathrm{Ca}$ montmorillonite. Their results also show that $\mathrm{Sr}$ and $\mathrm{Cs}$ adsorption on montmorillonite occurs by an ion exchange mechanism. Since the Kd concept can be derived from chromatographic ion exchange theory (Meyer 1979), it is not surprising that $K d$ values for montmorillonite are the same for batch and column methods.

Gee and Campbe11 (1980) have shown that batch and column techniques produced similar results for two soils taken from the Hanford Reservation in southeast Washington. Batch tests and unsaturated soil column tests with ${ }^{60}$ CO-EDTA, ${ }^{85} \mathrm{Sr},{ }^{95 m_{T c}}$, and ${ }^{125}$ I yielded $\mathrm{Kd}$ values that were less than $1.0 \mathrm{ml} / \mathrm{g}$, but the column tests did so with greater precision than the batch tests. Batch Kd measurements for small Kd values yielded effluent concentrations that were nearly the same as the influent concentrations. Thus, statistical variations in counting both influent and effluent activities can give standard deviations for Kd values that are comparable to the mean Kd values.

A comparison of batch and column Kd methods at Los Alamos Scientific Laboratory (Erdal et al. 1979), on the other hand, indicates that the two methods are not always equivalent. Using crushed material (granite, argillite, and tuff) for batch and column Kd determinations, the Los Alamos researchers have found that batch Kds are generally, but not always, higher than column Kd values. They have also shown that the ratio of batch $K d$ to column $K d$ increases in the order $\operatorname{Sr}(2 X), \operatorname{Cs}(3 X), B a(5 X)$. These three nuclides are added together (usually as a spike to the column and sometimes in a continuous feed influent with constant tracer concentration). Analysis of the ground water indicated that natural $\mathrm{Sr}$ and $\mathrm{Ba}$ concentrations were on the order of 
$0.1 \mathrm{ppm}$, which corresponds to $\approx 10^{-6} \mathrm{M}$ for both nuclides. Thus, the added tracer concentration (at or below $10^{-6} \underline{M}$ ) would have little affect on $\mathrm{Kd}$ values, since all measurements are made at essentially the same point on the sorption/desorption isotherm. If Kd values differed only because the surface areas exposed to solution were larger in the batch method than in column studies, then one might expect that all column $\mathrm{Kd}$ values ( $\mathrm{Sr}, \mathrm{Cs}$, and $\mathrm{Ba}$ ) should be decreased by the same factor, which is not the case. As yet, there is no definitive explanation for the observed discrepancy.

Discrepancies between batch and column methods may be explained in several ways. One possibility is that agitation of the slurry during a batch test actually grinds rock particles and causes their dissolution, resulting in 1) the formation of new minerals or precipitates with more surface area and/or higher sorptive capacity, and 2) the introduction of competing ions into the solution. Relatively soft materials, such as the montmorillonite mentioned previously, are not chemically affected as a consequence of grinding during agitation, which means that the ir respective batch and column test should agree. Meyer et al $(1977,1978)$ and Gee and Campbel1 (1980) have substantiated this point. Chemical effects as a result of grinding are not present during column tests, because the columns are not agitated.

Sorption kinetics could also be a reason that batch and column methods do not always agree. Equilibrium is not always attained using either batch or column methods. If, however, the geologic media are not altered by crushing, and if a suitable ground water is used, the batch method can (but does not necessarily) rapidly reach equilibrium. Dynamic sorption methods inherently produce disequilibrium states, for if flow velocities are high, radionuclides may pass through a column too rapidly for equilibrium to occur.

A comparison study of batch and column Kd values for $\mathrm{Cs}^{+}$on crushed basalt (Seitz 1979) has produced consistently higher Kd values for batch than for column experiments. Cesium concentrations were varied over several orders of magnitude in both types of experiments. Isotherms for both methods seem to be parallel (see Figure 1). Flow velocities $(4 \mathrm{~km} / \mathrm{yr}$ ) in the column experiment were faster than flow rates expected for a repository environment. Column experiments with lower flow velocities have also been conducted for $\mathrm{Cs}^{+}$on 
crushed basalt. If the amount of sorption previously observed in columns was really limited by kinetics, then $\mathrm{Kd}$ values determined at lower velocities were expected to approach those values determined by the batch method. As seen in Figure 1 , this is apparently true.

Column studies with intact, fractured, core material have been started (Erda1 1979). Intact cores of Climax Stock Granite (from the Nevada Test Site) containing natural fractures are placed in a column apparatus that simulates overburdens that confine pressure on the rock core. Radionuclide-traced ground water is forced through the core under a pressure less than that used for confinement, and the effluent is analyzed for breakthrough as in a normal column. After completion of a fracture-flow test, the rock core can be sectioned and analyzed to determine the radionuclide distribution. For alpha-emitting radionuclides, autoradiography can be used to determine which minerals adsorb a particular radionuclide. Results thus far have shown that it is difficult to force ground water through fractures in the granite. In several cores, ground water was found to flow around the core between the rock and a confining sleeve of Tefion.

In the batch and column comparisons made thus $f a r$, differences in measured $\mathrm{Kd}$ values are less than one order of magnitude. Experimental results have shown that the radionuclide concentrations and chemical compositions of ground water must be the same for making a comparison. Studies of the effects of retardation mechanisms in porous rock are needed to incorporate mechanism data obtained in batch studies. The study of fracture-flow systems is also needed to ensure that laboratory data are capable of satisfying the requirements for the safety assessment of deep-geologic, nuclear-waste repositories.

Trademark of the du Pont Co. 


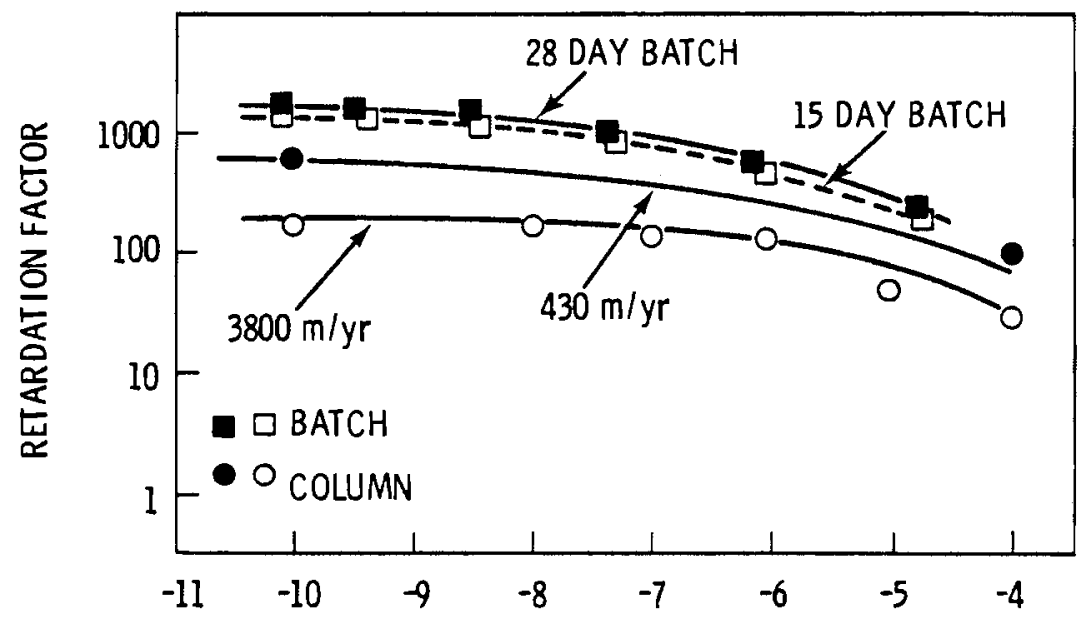

FIGURE 1. Adsorption of Cs-137 on Crushed Basalt: Comparison of Batch Kd Method and Column Method 


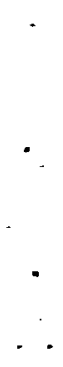




\section{REFERENCES}

Ballinger, D. G. 1979. "Metals; Atomic Absorption Methods" in Methods for Chemical Analys is of Water and Wastes. EPA-60014-79-020, U.S. Environmental Agency, Washington, D.C.

Barney, G. S. and G. E. Brown. 1979. "The Kinetics and Reversibility of Radionuclide Sorption Reactions with Rocks - Progress Report for Fiscal Year 1979." RHO-ST-29, Rockwe 11 Hanford Operations, Richland, Washington.

Bohn, H., B. McNeal and G. O'Connor. 1979. Soil Chemistry. WileyInterscience, New York, New York.

Brown, E., J. W. Skougstad and M. J. Fishman. 1970. Methods for Collection and Analys is of Water Samples for Dissolved Minerals and Gases: Book 5, Laboratory Analysis. U.S. Government Printing Office, Washington, D.C.

Coles, D. G., H. C. Weed and J. D. Tewhey. 1979. "Geochemical Studies of Sorption and Transport of Radionuclides in Rock Media" in Waste Isolation Safety Assessment Program. Task 4. Third Contractor Information Meeting Proceedings. ed. J. F. Relyea. PNL-SA-8571, Pac if ic Northwest Laboratory, Richland Washington.

Erda 1, B. R., R. Vidale, C. Duffy and D. C. Hoffman. 1977. "Laboratory Measurements of Radionuclide Distribution Between Selected Groundwater and Geologic Media" in Waste Isolation Safety Assessment Program. Task 4. Second Contractor Information Meeting: Vol. II. ed. R. J. Serne. PNL-SA-7352, Pacific Northwest Laboratory, Richland Washington.

Erdal, B. R., R. D. Aguilar, B. P. Bayhurst, G. E. Bentley, W. R. Daniels, S. J. DeVilliers, F. O. Lawrence, S. Maestas, P. Q. Oliver, J. L. Thompson, E. N. Vine and K. Wolfsberg. 1977. "Laboratory Studies of Radionuclide Distribution Between Selected Groundwater and Geologic Media" in Waste Isolation Safety Assessment Program. Task 4. Third Contractor Information Meeting Proceedings. ed. J. F. Relyea. PNL-SA-8571, Pac if ic Northwest Laboratory, Richland Washington.

Gee, G. W. and A. C. Campbe11. 1980. Monitoring and Physical Characteriza tion of Unsaturated Zone Transport - Laboratory Analysis. PNL-3304, Pacif ic Northwest Laboratory, Richland, Washington.

Hostetler, D. D., R. J. Serne and A. Brandstetter. 1979. Status of Sorption Information Retrieval System. PNL-3139, Pacific Northwest Laboratory, Richland, Washington. 
Meyer, R. E., S. Y. Shiao, P. Rafferty, J. S. Johnson, I. L. Thomas and K. A. Kraus. 1977. "Systematic Study of Nuclide Sorption on Select Geologic Media" in Waste Isolation Safety Assessment Program. Task 4. Contractor Information Meeting Proceedings. ed. R. J. Serne. PNL-SA-6957, Pacific Northwest Laboratory, Richland, Washington.

Meyer, R. E. 1978. "Systematic Study of Nuclide Sorption on Select Geologic Media" in Waste Isolation Safety Assessment Program. Task 4. Second Contractor Information Meeting: Vol. II. ed. R. J. Serne. PNL-SA-7352, Pacific Northwest Laboratory, Richland Washington.

Meyer, R. E. 1979. "Systematic Study of Nuclide Sorption on Select Geologic Media" in Waste Isolation Safety Assessment Program. Task 4. Third Contractor Information Meeting Proceedings. ed. J. F. Relyea. PNL-SA-8571, Pacific Northwest Laboratory, Richland Washington.

Rai, D., R. J. Serne and D. A. Moore. 1977. "Identification of Plutonium Compounds and The ir Solubility in Soils." in Waste Isolation Safety Assessment Program. Task 4. Contractor Information Meeting Proceedings. ed. R. J. Serne. PNL-SA-6957, Pacific Northwest Laboratory, Richland, Washington.

Relyea, J. F., R. J. Serne, D. Rai and M. J. Mason. 1977. "Batch Kd Experiments with Common Minerals and Representative Groundwaters" in Waste Isolation Safety Assessment Program. Task 4. Contractor Information Meeting Proceedings. ed. R. J. Serne. PNL-SA-6957, Pacific Northwest Laboratory, Richland, Washington.

Relyea, J. F., L. L. Ames, R. J. Serne, R. W. Fulton and C. W. Washburne. 1978. "Batch Kd Determinations with Common Minerals and Representative Groundwaters" in Waste Isolation Safety Assessment Program. Task 4. Second Contractors Information Meeting: Vol. II. ed. R. J. Serne. PNL-SA-7352. Pacific Northwest Laboratory, Richland, Washington.

Relyea, JiF., C. D. Washburne and R. W. Fulton. 1979a. Sorption Behavior of ${ }^{85} \mathrm{Sr},{ }^{137} \mathrm{Cs}$ and $95 \mathrm{~m} \mathrm{Tc}$ Under Norma 1 Atmospher ic and Reduced Oxygen Levels. PNL-SA-7928, Pac ific Northwest Laboratory, Richland, Washington.

Relyea, J. F., R. J. Serne, R. W. Fulton, C. D. Washburne and W. J. Martin. 1979b. Laboratory Studies of Pu-237 Sorption on Selected Minerals Under Anoxic Conditions. PNL-SA-7989, Pacific Northwest Laboratory, Richland, Washington.

Relyea, J. F. and R. J. Serne. 1979c. Controlled Sample Program Publication Number 2: Interlaboratory Comparison of Batch Kd Values. PNL-2872, Pacific Northwest Laboratory, Richland, Washington. 
Relyea, J.F., Ohanpat Rai and R. J. Serne. 1979d. "Interaction of Waste Radionuclides with Geomedia: Program Approach and Progress." in Proceedings of the Symposium on "Science Underlying Radioactive Waste Management, "Materials Research Society Annual Meeting, Boston, Massachusetts, November 28December 1, 1978. pp. 379-394. ed. G. J. McCarthy. Plenum Press, New York, New York.

Seitz, M. G., P. G. Rickert, R. Couture, J. Williams, S. M. Fried, A. M. Friedman and M. J. Steindler. 1979. "Transport of Radionuclides in Geologic Media: Annual Report." in Waste Isolation Safety Assessment Program. Task 4. Third Contractor Information Meeting Proceedings. ed. J. F. Relyea. PNL-SA-8571, Pacific Northwest Laboratory, Richland, Washington.

Serne, R. J. ed: 1977. Waste Isolation Safety Assessment Program. Task 4. Contractor Information Meeting Proceedings. PNL-SA-6957, Pac if ic Northwest Laboratory, Richland, Washington.

Serne, R. J. ed. 1978. Waste Isolation Safety Assessment Program. Task 4. Contractor Information Meeting Proceedings. PNL-SA-7352, Pacific Northwest Laboratory, Richland, Washington.

Triolo, Roberto, Neva Harrison and Kurt A. Kraus. 1979. "Use of the Axial Filter to Measure Low Distribution Coeffients." Jour. of Chromatography. 197:19-35. 


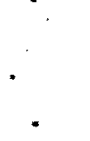

. 
APPENDIX A

PROPOSED STANDARD BATCH Kd PROCEDURE 
APPENDIX A

\section{PROPOSED STANDARD BATCH Kd PROCEDURE}

\subsection{GEOLOGIC MATERIAL PREPARATION}

1.1.0 For radionuclide migration/retardation studies, aquifer materials should be selected from the most likely pathways that connect a deep geologic repository and the biosphere. Aquifer material in the form of unconsolidated sediments, loosely consolidated sediments, or consolidated porous material may be obtained in a core during a site-specific geologic investigation. (For a batch study, consolidated, porous rock and intact, impermeable rock may be treated using the same procedures.)

Bulk chemical analysis, mineralogy, surface area (using the ethylene-glycol/monoethyl-ether method) and cation exchange capacity should be determined for each sample (as outlined in the recommendations section). For further reference, see the following publications:

- Surface Area--Cihacek, L. J., and J. M. Bremner. 1979. "A Simplified Ethylene Glycol Monoethyl Ether Procedure for Assessment of Soil Surface Area." Soil Sci. Soc. Am. J., 43:821-822.

- Cation Exchange Capacity--Chapman, H. D. 1965. "Cation-Exchange Capacity." In Methods of Soil Analys is Agronomy, 9:891-901, ed. C. A. Black. Am. Soc. of Agron., Madison, WI.

Treatment for each type of aquifer material will be as follows.

1.1.1 Unconsolidated Material: To remove particles greater than one millimeter $(>1.0 \mathrm{~mm})$, the sample shall be wet-sieved with ground water by passing the sample through a No. 18 stainless steel sieve. If tests with the material are to be conducted in an inert atomsphere or in a controlled atmosphere, rock samples should be prepared under those same atmospheric conditions. This requires minimum contact of the rock with air from the time it is removed from the earth until the time the experiment is concluded. This condition holds for Sections 1.1 .2 and 1.1.3. The particle size shall be determined and reported with results from Section 1.1.0. 
1.1.2 Loosely Consolidated Material: The sample shall be disaggregated by an ultrasonic method or by hand with a mortar and pestle. A portion of the intact material should be preserved for dynamic testing. Disaggregation shall proceed no farther than that required to reduce the sample to its natural grain size. Fresh surfaces will be exposed to weathering, but this procedure should reduce fracturing of particles to a minimum. Remove particles $>1.0 \mathrm{~mm}$ as in Section 1.1.1. The particle size distribution after disaggregation shall be reported with results in Section 1.1.0.

\subsubsection{Consolidated Porous Material (and intact, impermeable rock): A} portion of the intact sample should be preserved (and maintained under conditions that simulate those in situ) for dynamic testing. The remaining sample should be crushed to pass through a No. 18 sieve $(<1 \mathrm{~mm})$. Crushing should be accomplished by means that minimize the introduction of extraneous material, such as metal filings, into the sample. The sample should then be wet sieved on a No. 50 sieve $(0.30 \mathrm{~mm})$ to obtain particle sizes between $0.30 \mathrm{~mm}$ and $1.00 \mathrm{~mm}$.

1.2.0 After samples have been sized (Sections 1.1.1, 1.1.2 or 1.1.3), they must be homogenized to insure that the same particle size distribution is obtained for each subsample to be studied.

1.2.1 After homogenizing, one-gram $(1.0 \mathrm{~g} \pm 0.01 \mathrm{~g})$ samples are to be weighed (and weights recorded) into tared, 50-ml polycarbonate centrifuge tubes with screw caps. Centrifuge tube threads should be wrapped with teflon tape to prevent leaks.

1.3.0 Thirty-milliliters of filtered, unspiked (no radioactive tracer) ground water is added to each tube for a "cold" wash. The tube caps should be replaced before the tubes are placed on a shaker for a gentle overnight agitation (about one oscillation per second).

1.3.1 The tubes should next be centrifuged for 20 min at $5,000 \mathrm{~g}(\mathrm{~g}=$ $980 \mathrm{~cm} / \mathrm{sec}^{2}$ ). The solution should then be removed with a vacuum pipette to prevent removal of the rock sample (some liquid will remain in the tube). 
1.3.2 The wash procedure should be repeated twice more for a total of three cold (nonradioactive) washes. Before the centrifuge step on the third wash, the $\mathrm{pH}$ of the solid-solution should be measured and recorded. If the $\mathrm{pH}$ has changed from its natural equilibrium value as measured in the field, the rock sample and ground water have not yet re-established equilibrium. Continue to wash until the $\mathrm{pH}$ is stable. A change in $\mathrm{pH}$ is most likely to occur with samples of crushed rock (Section 1.1.3), because fresh surfaces (either rock or cementing agents) have been exposed.

1.3.3 After removal of the third wash solution, each tube must be reweighed and the weight must be recorded to determine the volume of excess solution left in each sample. The cap of each tube should be secured to prevent evaporation, which would result in in an increased salt concentration in the remaining solution. The excess solution volume is found by dividing the excess solution weight by the solution density.

\subsection{GROUND-WATER PREPARATION}

2.1 If possible, ground water from the aquifer to be studied should be used in batch Kd measurements. Three subsamples (one liter each) should be taken during sampling and preserved according to USGS guidelines for trace metals and nutrients (Brown et al, 1970). Bulk ground-water samples (30 gallons or more) must be placed in a polyethylene-lined, airtight drum and flushed with nitrogen to prevent the oxidation of reduced species. The ground water should come in minimum contact with air (preferably none), because exposure to air will oxidize $\mathrm{Fe}^{+2}$ to $\mathrm{Fe}^{+3}$, which then precipitates and alters the redox potential (Eh).

2.2 Ground water should be filtered before it is used in a batch $\mathrm{Kd}$ measurement. Particles greater than $0.45 \mu \mathrm{m}$ should be removed by passing the solution through a $0.45 \mu \mathrm{m}$ polycarbonate membrane filter as suggested by the EPA (Ballinger 1979). If the ground water has been stored for more than one month after the initial chemical analysis, analysis of major constituents ( $\mathrm{Ca}$, $\mathrm{Mg}, \mathrm{Na}, \mathrm{K}, \mathrm{Cl}, \mathrm{NO}_{3}, \mathrm{SO}_{4}, \mathrm{CO}_{3}$ and $\mathrm{HCO}_{3}$ ) should be repeated before continuation of the experiment. If retardation parameters (such as $\mathrm{pH}$, ionic 
strength, and complexing ligand concentration) are to be studied, the synthetic or altered ground water should be chemically analyzed after preparation and filtration.

\subsection{ADDITION OF TRACER RADIONUCLIDE TO GROUND WATER}

3.1 The adding of tracer to a solution represents a critical step in the execution of radionuclide migration studies. Two items must be carefully considered: 1) the total amount of tracer added should be soluble in the volume of solution used; and 2) the chemical composition of the ground water or synthetic ground water must remain unchanged, except for the addition of the radionuclide(s) to be studied.

3.2 Tracers should be dried so that excess acid or base in the stock solution is removed. The researcher should be familiar with the chemical behavior of the $\operatorname{tracer}(s)$ so that the tracer is not volatilized during the drying procedure. For example, technetium and iodine should not be dried in acid media or they will be lost by volatilization. The chemical form produced by drying should be soluble in the solutions used in experimentation. (An incorrect procedure would be to dry plutonium in basic media that would produce an insoluble $\mathrm{PuO}_{2}$ or $\mathrm{Pu}(\mathrm{OH})_{4}$ precipitate).

3.3 Exception to the dry-addition rule must be made in some cases for radionuclides that have multiple oxidation states. When drying might change the tracer stock solution's oxidation state--such as $\mathrm{PU}$ (VI) to $\mathrm{Pu}$ (IV)--tracer should be added to solution in as small a volume as possible with as little excess salt and acid or base as possible. Otherwise, a dry, soluble, salt-free tracer shall be added to ground water.

3.4 Tracer solution should be allowed to sit for at least one week under conditions to be used in the experiment (in equilibrium with air if the aquifer is in equilibrium with air, or under controlled atmosphere conditions if the aquifer is not in equilibrium with air). Adjustments to $\mathrm{pH}$ should be made during the equilibration time, if required. Solution should be filtered $(0.45 \mu \mathrm{m})$ after equilibration prior to contact with the geologic material. 
3.5 The amount of tracer present in the ground water just prior to contact with the rock should be calculated (moles per liter). Any carrier isotope of the element added with the tracer and any natural occurrence of the element in ground water should also be reported.

\subsection{ROCK AND GROUND-WATER CONTACT}

4.1 Thirty milliliters $(30 \mathrm{ml})$ of filtered ground water containing the radioactive tracer is added to each sample tube containing one gram ( $1 \mathrm{~g})$ of solid. In addition, $30 \mathrm{ml}$ of spiked ground water is placed in each of three empty (blank) centrifuge tubes (prewashed as in Section 1.3). The blank tubes are needed to detect sorption of tracer by centrifuge tube walls. If actual effluents cannot be conveniently analyzed, a cold ground-water/washed aquifer material (Section 1.3) sample should also be run to facilitate characterization of the ground-water composition at time of Kd determination.

4.2 After replacing tube caps, the tubes are placed in plastic bags ( 5 to 20 tubes per bag) to contain any contamination caused by leaky tubes. Next, the tubes are placed on a shaker (for linear reciprocating shaker, place tubes horizontally) so that the solid-solution mixture makes maximum contact. The shaking speed should be set at 0.8 to 1.2 oscillations per second to ensure mixing of solid and liquid but to reduce grinding of particles.

4.3 Contact between solid and liquid should be seven days ( 7 days) if time is not a parameter being studied. The samples are then removed from the shaker and the tubes are visually checked for leaks (decontaminate if necessary and discard leaky tubes). The blank tubes then are analyzed for total activity.

4.4 The blank and sample tubes are centrifuged for twenty minutes (20 min) at $10,000 \mathrm{~g}\left(\mathrm{~g}=980 \mathrm{~cm}-\mathrm{sec}^{-2}\right)$ or more, and fifteen milliliters $(15 \mathrm{ml})$ of effluent is filtered through a pre-washed $0.45 \mathrm{~m}$ polycarbonatemembrane-type filter. (Pre-wash with ground water from Section 2.2 to remove foreign particles and soluble impurities.) Filtered effluent samples should then be analyzed for tracer activity. Next, the effluent is decanted from the blanks into cleanly washed tubes and the empty blank tubes are analyzed for 
tracer activity adsorbed on tube walls. If tracer activity on blank tube walls is greater than $10 \%$ of the total blank activity (determined in Section 4.3), the blank influent activity should not be used for Kd calculation. If the activity sorbed on blank walls is significantly greater than $10 \%$ (using a one-tailed " $t$ " test and combined counting error and statistical variation between blanks), direct counting of activity of the sample should be used. Methods for both cases follow.

\subsection{BATCH Kd CALCULATION WHEN TRACER IS NOT SORBED BY BLANK TUBE WALLS}

5.1 Data needed for Kd calculation are: 1) excess solution volume, $x$, (m1) left from the third cold wash (weight of excess solution divided by solution density); 2) weight, $W$, of solid aquifer material, $(g)$; 3) volume, $V$, of ground water with radioactive tracer added $(\mathrm{ml}) ; 4)$ activity of tracer in the effluent, $E$, solution $(\mathrm{dpm} / \mathrm{ml})$; and 5$)$ the tracer activity in the influent blank, $B,(d p m / m 1)$.

5.2 The tracer concentration on the solid phase is:

$$
[B V-E(V+X)] / W
$$

The $K d$ is then given by:

$$
K d=\frac{B V-E(V+X)}{W E}
$$

or

$$
K d=\frac{V}{W}\left(\frac{B}{E}-1\right)-\frac{X}{W}
$$

6.0 BATCH Kd CALCULATION WHEN TRACER IS SORBED BY BLANK TUBE WALL (Gamma or X-ray Emitting Isotopes)

6.1 If the radioactive tracer is adsorbed on the walls of blank tubes, the tracer adsorbed by the solid should be determined by direct measurement. 
Using a stock solution of known activity (traceable to an NBS standard), a known volume of solution $(1 \mathrm{ml})$ is dried on $1 \mathrm{~g}$ of solid aquifer material in a polycarbonate centrifuge tube. The dried solid is transferred to a clean tube and the drying tube is counted to determine the amount of traced dried on the tube surface (should be less than $5 \%$ of the total activity). The dried, spiked solid is now a standard used to determine the attenuation factor (A) for the gamma or X-rays emitted from isotopes used in sorption experiments.

6.2 For this procedure, after the rock and traced ground water have contacted for at least 7 days, the samples are centrifuged as in Section 4.4, and then the liquid effluent is decanted from the sample tube using a vacuum pipette, and the sample is weighed to determine the residual effluent solution volume ( $X$ = residual solution weight/solution density). The solid sample is then dried (it should be "air dried" in the same manner as when originally weighed, either in air or in a controlled atmosphere) and transferred to a clean polycarbonate centrifuge tube. The weight of the dry sample $W^{*}(g)$ is then determined and radiocounting of the dry sample is performed for tracer activity, C (dpm), using the same detector, sample position, and radioanalytical techniques as used for the attenuation standard prepared in Section 6.1.

6.3 Effluent tracer activity, $E(\mathrm{dpm} / \mathrm{ml})$ should be determined in geometries that are traceable to an NBS Standard. The Kd can then be calculated from:

$$
K d=\frac{C-E X}{W^{\star} E}
$$

\subsection{BATCH Kd CALCULATION WHEN TRACER IS SORBED BY BLANK TUBE WALL}

(Alpha- or Beta-Emitting Isotopes)

If the radioactive tracer is adsorbed by sample container walls, only the effluent activity can be determined simply and directly. Two options are available for determination of the activity adsorbed by the rock sample. One method is to remove both the solid sample and effluent from the original 
container and to strip the isotope from the container wall by some means. Mass balance will allow calculation of the $\mathrm{Kd}$ if one knows the amount of radionuclide in the effluent on the tube wall and the total radionuclide initially added. A second method is to chemically remove the radionuclide from the rock sample and count it.

Problems with the first method include the possibility that some of the solid may adhere to the wall and raise the apparent activity of the nuclide adsorbed by the container. Removal of the solid sample may also cause leaching of the container wall and result in an apparent low activity for nuclides adsorbed by the container.

The second method is subject to incomplete removal of the nuclide from the solid or loss of material during any additional steps required for extraction, or both. 
APPENDIX B

REPORTING RESULTS FROM RADIONUCLIDE MIGRATION EXPERIMENTS 


\section{APPENDIX B}

\section{REPORTING RESULTS FROM RADIONUCLIDE}

MIGRATION EXPERIMENTS

The investment of time and money in the study of radionuclide migration and the usefulness of the obtained data make reporting results a vital part of the research effort. A standard format for reporting results has been developed by Serne (1977) and revised by Hostetler, Serne and Brandstetter (1979). The following is an outline of the recommended generic Kd coding form used at PNL. (Coded results from a batch Kd experiment using microline are included as an example at the end of this section.)

\section{Generic Kd Coding Form}

\section{(Revision 1)}

\section{Reference}
A. Name
B. Lab
C. Source
D. Quality
E. Oate Submitted

\begin{abstract}
Exp. Details
\end{abstract}

\begin{abstract}
A. Method
\end{abstract}
B. State

C. Ratio

D. Time

E. Temp

F. ATM

G. SEP

H. Analyze

I. Rad
Geologic Media

A. Name

B. Origin

C. Total

o. Mineral

E. $\mathrm{CO}_{3}$

Aqueous Phase

A. When

B. Macro

C. Trace

Pase

Nuclide

A. Iso

B. Conc

C. Spe

D. Add

E. Loading
Adsorption Function

A. $\mathrm{Kd}$

B. Units

C. Dir

D. Num 


\section{EXPLANATION OF Kd CODING FORM (REVISION 1)}

\section{Category I. Reference}

A. Name of Investigator who is reporting results, the person who performed experiments, or the person most capable of answering questions about the data. We would like to be able to track each data point back to a knowledgeable person.

B. Lab affiliation of investigator named in $A$.

C. Source where one could find the results published and described. Please use the following format:

Author's name, (date), title of paper, journal or lab report and number, publisher where applicable, page number.

If unpublished, use UNP.

D. Quality refers to one's confidence in the data. A critical assessment should be performed which includes identification of limitations, such as lack of certain parameter characterization, unexplained perturbations, etc. For conc iseness, we have chosen a five-category value system:

1. Excellent quality

2. Above average quality

3. Average quality

4. Below average quality

5. Poor quality

Because this categorization is arbitrary, comments as to why you gave the data a certain rating are welcome. We would consider the "excellent" category to include Kd data whose complete characterization of media, solution, and nuclide are available. Also, for an "excellent" rating, the test results should have been reproduced several times with good precision.

"Average quality" would leave some characterization work ill-defined (those which are least important and most costly to determine, have not been reproduced, or have precision no better than $\pm 30 \%$ ). 
"Below average" data show meager system characterization, little reproductibility, or identified experimental limitations.

E. For quality assurance purposes, each data point needs to be dated as to when it was submitted to the computer (calendar year).

\section{Category II. Experimental Details}

A. Method refers to batch, axial filter, column, intact core, channel chromatography, and so forth. For batch method, add more detail as to whether cold washes and blank corrections were used. For example, use mnemonics such as

BATCH $(3 W, B C)=$ batch, three cold washes, with blank tube sorption correction

BATCH $(O W)=$ batch, zero cold washes and no correction.

B. State of geologic media such as crushed $40 \mu \mathrm{m}$; intact core $2.5 \mathrm{~cm}$ dia $\mathrm{x}$ $5 \mathrm{~cm}$; tablet $1 \mathrm{~cm} \times 0.5 \mathrm{~cm}$; crushed $30-80 \mu \mathrm{m}$, etc.

C. Ratio of solids to solution for batch $\mathrm{Kd}$; for columns include pore velocity or column velocity (for example, $1 \mathrm{PV}=1 \mathrm{~cm} / \mathrm{hr} \quad \mathrm{CV}=0.5 \mathrm{~cm} / \mathrm{hr}$ ) and porosity and column bulk density; $P R=$ porosity $B d=$ bulk density.

D. Time of contact such as shaking time for batch system or residence time in flow through columns $(h)=$ hours, $(d)=$ days.

E. Temp is the temperature of the experiment in ${ }^{\circ} \mathrm{C}$.

F. ATM is the equilibrating atmosphere air, $\mathrm{N}_{2}, \mathrm{Ar}, 10 \% \mathrm{CO}_{2}-90 \% \mathrm{Ar}$, and so forth.

G. Sep stands for separation technique; did you use filters (give median pore size) or centrifugation; (include approximate $g^{\prime} s$ )?

$\operatorname{FIL}(.4)=$ filter $0.4 \mathrm{~m}$

CEN $(50)=$ centrifuged at $50 \mathrm{~g}$ 's where $g=980 \mathrm{~cm} / \mathrm{sec}^{2}$ units.

$H$. Count states whether the $K d$ is determined by counting liquids on $1 y$ or solid and liquid:

$L / L=7$ iquids only

$S / L=$ solid and liquid 
I. RAD. List other radioisotopes that were run simultaneously in the experiment just in case we determine that certain nuclides affect other nuclides.

Example: $\mathrm{Sr}, \mathrm{CS}$, TC means these isotopes were run together.

\section{Category III. Geologic Media}

A. Name. Use the generic name of the rock or mineral, e.g., basalt, granite, montmorillonite.

B. Origin. Include a geographic description and some formation information, e.g., Eleana shale, Sentinel Gap basalt, Argillaceous Shale Wards \#404561.

C. Total. Identify the chemical composition as oxides $\left(\mathrm{SiO}_{2}, \mathrm{Al}_{2} \mathrm{O}_{3} \mathrm{TiO}_{2}\right.$, $\mathrm{FeO}, \mathrm{Fe}_{2} \mathrm{O}_{3}, \mathrm{MnO}, \mathrm{CaO}, \mathrm{MgO}, \mathrm{K}_{2} \mathrm{O}, \mathrm{Na}_{2} \mathrm{O}, \mathrm{P}_{2} \mathrm{O}_{5}$ in $\%$.

D. Minerals. Identify the minerals present in the rock sample, listing the major ones first, the minor ones last, in the order of the composition percentages in which they appear ( 1 argest first). If there are quantitative estimates, add this information as $\%$ and $t r=5 \%$.

E. $\underline{\mathrm{CO}}_{3}=$ carbonate content of rock.

F. $\underline{O X}=$ hydrous $\mathrm{Fe}, \mathrm{Mn}, \mathrm{Al}$ oxides content of rock.

G. $\quad \underline{C E C}=$ cation exchange content of material; units $=$ meq $/ 100 \mathrm{~g}$. Specify $\mathrm{pH}$ of system (typically $\mathrm{pH}=7$ ).

H. $\underline{A E C}=$ anion exchange content of material; units $=$ meq $/ 100 \mathrm{~g}$. Specify $\mathrm{pH}$ of system.

I. $\underline{S A}=$ surface area; use "EG" for ethylene glycol, "BET" for gas adsorption, use units $\mathrm{m}^{2} / \mathrm{g}$, for example, $\mathrm{EG}(1.3)$.

\section{Category IV. Aqueous Phase}

A. When measured; BEG signifies before tracer adsorption begun, END signifies at the same time as Kd determined. 
B. Macro Constituents include:

(1) $\mathrm{pH}$

(2) Eh (units vs S.H.E.)

(3) $\mathrm{Na}^{+}$

(4) $\mathrm{Ca}^{+2}$

(5) $\mathrm{K}^{+}$

(6) $\mathrm{Mg}^{+2}$

(7) $\mathrm{Cl}^{-}$

(8) $\mathrm{HCO}_{3}{ }^{-} ; \mathrm{CO}_{3}=$

(9) $\mathrm{SO}_{4}=$

(10) $\mathrm{SiO}_{4}$

C. Trace constituents include:

(11) $\mathrm{NO}_{3}, \mathrm{ppm}$

(12) Organic carbon

(13) B

(14) Trace metals or anything else measured.

Category V. Nuclide

A. ISO. Isotope used such as ${ }^{237} \mathrm{Pu},{ }^{95 \mathrm{~m}} \mathrm{Tc}$.

B. CONC. Concentration added to ground water in $M=$ molarity. Include any carrier if present.

C. SPE. Species or valence state added, if known. Also state whether the valence state distribution was determined after equilibration state, e.g.,

Pu(VI)BEG; Pu(IV) 15\%, Pu(V) 50\%, Pu(VI) 10\%END

(which means that the original spike was $100 \% \mathrm{Pu}(\mathrm{VI})$, and after shaking the final distribution was as shown).

D. ADD describes how the tracer was added to the ground water; DRY means evaporated to dryness and gw added; WET/PH/3DF0.4 means a small aliquot of liquid tracer was added to the ground water, the system was re-pH'ed to the appropriate value and shaken for 3 days to filtration through $0.4 \mu \mathrm{m}$ filters before usage. 
DRY/1DC50 means the dried spike was brought back into solution equilibrated for one day, and centrifuged at $50 \mathrm{~g}$ 's before usage.

E. Loading describes (a) the percent of total exchange capacity of the adsorbent fill with the nuclide of interest or (b) the mass of nuclide adsorbed/ mass of adsorbent at the condition when the Kd measurement is performed. This value can be calculated from knowledge of the cation or anion exchange capacity in case (a) and from mass balance considerations. One must know the original mass of the nuclide used in each experiment.

\section{Category VI. Adsorption Function}

A. Kd. Place the value for Kd or Rd, whatever you prefer to call it. If a retardation factor is determined in a flow-through column as a function of water velocity, designate by the symbol RF.

Where several measurements were made, also give the standard deviation, such as

$75 \pm 12=\mathrm{a} \mathrm{Kd}$

(RF) $60 \pm 30$ = retardation factor

B. UNITS. $\mathrm{ml} / \mathrm{g}$ or $\mathrm{ml} / \mathrm{m}^{2}$ or LESS = unitless

C. DIRECTION. ADS = adsorption direction

DES = desorption direction

A spike addition to a column would be ADS-DES.

D. $\underline{N U M}=$ number of observations used to derive data point, for example $3=$ triplicate samples. 


\section{Example of Batch-Kd Experiment}

\section{PNL Batch Kd for Microcline}

\section{Ref erence}

A. J. F. Relyea

B. PM

C. WISAP Task 4 Contractor's Information Meeting Proceedings,

0ctober 2-5 1978 , $2-5$ PNL-SA-7352

D. 2

四 1978

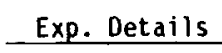

A. Batch $(3 W, B C)$

B. Crushed $100 \mathrm{~m}$

C. $0.5 \mathrm{~g} / 15 \mathrm{ml}$

D. $29 d$

E. $25 \mathrm{C}$

F. Air

G. Cen $(70)$

H. L/L

I. $\mathrm{Sr}, \mathrm{Cs}$
A. Microcline

B. Parry Sound Ontario (Ward's Scientific)

C. $\mathrm{SiO}_{2} \quad 67.5$

$\begin{array}{ll}\mathrm{Al}_{2} \mathrm{O}_{3} & 17.1 \\ \mathrm{TiO}_{2} & \mathrm{~N} . \mathrm{D}\end{array}$

$\mathrm{TiO}_{2}$ N.D.

$\begin{array}{ll}\mathrm{FeO} & 1.8 \\ \mathrm{MnO} & \text { N.D. }\end{array}$

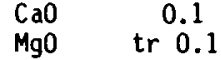

$\mathrm{K}_{2} \mathrm{O} \quad 13.6$

$\begin{array}{ll}\mathrm{Na}_{2} \mathrm{O} & \mathrm{N} . \mathrm{D} \\ \mathrm{P}_{2} \mathrm{O}_{5} & \text { tr } 0.1\end{array}$

D. Microcline - $83 \%$ $\left(\mathrm{K}_{3.95}\right)\left(\mathrm{Al}_{3.95}\right.$

Sl 12.05$) 032$
Quartz $-15 x$

$\left(\mathrm{SiO}_{2}\right)$

Calcite -1 to $2 x$

$\left(\mathrm{CaCO}_{3}\right)$

Garnet - $1 x$

Almandine-Pyrope

Garnet, ( $\mathrm{Fe}_{2} .69$

$\mathrm{Mg}_{4} .14$ ) ( $\mathrm{Fe}_{1.00}$

A] $.47, \mathrm{Si}_{5.53}$ )

$\mathrm{O}_{24}$

E. $1 x$

F. Not determined

G. $1.2 \pm 0.2, \mathrm{pH}=7$

H. Not determined

I. E.G. $(6.1 \pm 1.0)$
A. Beg.

Aqueous Phase

B.

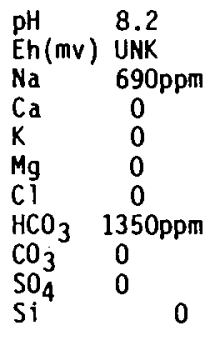

c. $\begin{array}{lr}\mathrm{NO}_{3} & \text { UNK } \\ 0 . C . & \text { UNK } \\ \mathrm{B} & \text { UNK } \\ \text { Tr.Mat } & \text { UNK }\end{array}$

B.

C.
Nuclide

\section{A. End}

$\mathrm{pH} 9.25$

Eh(mv) 312

$\begin{array}{rr}\mathrm{Na} & 654 \mathrm{ppm} \\ \mathrm{Ca} & 4 \mathrm{ppm}\end{array}$

$\mathrm{K} \quad 20 \mathrm{ppm}$

$\begin{array}{ll}\mathrm{Mg} & 0 \\ \mathrm{Cl} & 9.4 \mathrm{ppm}\end{array}$

$\mathrm{HCO}_{3} 1571 \mathrm{ppm}$

$\begin{array}{ll}\mathrm{HCO}_{3} & 1571 \mathrm{ppm} \\ \mathrm{CO}_{3} & 75 \mathrm{ppm}\end{array}$

$\mathrm{CO}_{3} \quad 75 \mathrm{ppm}$

$\mathrm{Si}^{4} \quad 30 \mathrm{ppm}$

$\begin{array}{ll}\mathrm{NO}_{3} & \text { UNK } \\ 0 . \mathrm{U} & \text { UNK }\end{array}$

$\begin{array}{lr}\text { O.C. } & \text { UNK } \\ \text { B } & 2.8 \mathrm{ppm}\end{array}$

Tot.Fe $9.1 \mathrm{ppm}$

Tot.P $\quad 0.2 \mathrm{ppm}$
A. TC

B. (approx.) $1 \times 10^{-8}-8$

C. $\mathrm{TCO}_{4}^{-1}$ Beg

D. Wet/pH/7DF 0.45

E. Not determined
Adsorption-Function

A. $0.61 \pm .13$

B. $\mathrm{ml} / \mathrm{g}$

C. Adsoption

D. 3 reps 
.

.

. $\cdots$ 
APPENDIX C

COLUMN PROCEDURES AND DATA REPORTING 


\section{COLUMN PROCEDURES AND DATA REPORTING}

\subsection{ROCKS}

Any material that can be used for a batch sorption/retardation experiment can generally be used in a column experiment. The major advantage of using a column instead of a static test, aside from being able to study hydrodynamic effects, is that more realistic solution-to-solid ratios can be used. Intact samples of aquifer material should be used for dynamic tests whenever possible. However, dense, impermeable rocks may require crushing for use in low-pressure column work.

\subsection{GROUND WATER}

Ground-water samples or synthetic ground water should be prepared with the same restrictions that are applied to the use of solutions in batch experiments. Geologic media and ground water should be at equilibrium before beginning a column retardation experiment. Methods for adding tracer to ground water are the same for batch and column experiments.

\subsection{APPARATUS}

Radioactive tracer experiments using columns should be conducted with materials that keep sorption of tracer by the apparatus to a minimum (such as teflon-lined solvent delivery tubes, solution reservoirs, and geologic-media confinement vessels). Experimental setups generally consist of: 1) a reservoir to contain ground water traced with a radionuclide; 2) a solvent delivery system for transport of ground water from the reservoir to the column; 3) the column, which serves as a confinement vessel for the rock being studied; and 4) a system to collect effluent for analysis (e.g., a fraction collector).

The ground-water reservoir should be made of an inert material to prevent solution composition changes caused by sorption on container walls. The 
reservoir should also be airtight to prevent the loss of solution by evaporation, and the introduction of gases or particulates from the atmosphere.

Solvent delivery systems may vary widely, ranging from a gravity-feed-type for use with low-pressure, high-permeability rocks, to a high-pressure system requiring a high-pressure pump and teflon-lined stainless steel tubing for use with dense, low-permeability rock cores.

Confinement vessels also vary widely according to the pressure (safety) requirements. The sample containment vessel should also be inert with respect to the radionuclide being studied.

Sample collection systems range from a bottle under the column to automated fraction collectors. Care should be exercised to insure that sample loss does not occur by evaporation and that the effluent volume passing through the column is known. Post column mixing should be reduced by keeping the tubing from the column to the fraction collector as short as possible.

Low-pressure, saturated-column experiments are best run in an upflow mode. Influent should enter the column from the bottom and exit as effluent from the top. Application of the upflow technique helps to prevent clogging of small pores by air bubbles (which may not be much of a problem with unsaturated or high-pressure column experiments).

\subsection{DATA REPORTING AND INTERPRETATION}

Data required for interpretation of a column experiment (but not for a batch experiment) include: pore or void volume; porosity; bulk density; pore water velocity; column dimensions; and the radionuclide concentration in each effluent sample. Mineral or rock parameters and ground-water compositions should be reported as shown in Appendix B. The time should be reported for both the duration of the experiment and for the time it takes one pore volume of solution to pass through the column.

For porous media, many parameters can be determined from a few basic measurements of porosity $\Sigma$, bulk density $\rho_{b}$, column dimensions $L$ and $r$, and the volumetric flow rate $Q\left(\mathrm{~cm}^{3} /\right.$ day $)$. Definitions for the measured parameters follow. 
$L=$ length of the column $(\mathrm{cm})$.

$r=$ radius of the column $(\mathrm{cm})$ on half the inside diameter.

= porosity of the column. This parameter may be thought of as an absolute measurement, but is in fact subject to some interpretation. Two definitions will be given for the porosity.

PR-S = static porosity $\left(\mathrm{cm}^{3} / \mathrm{cm}^{3}\right)$ is the volume of the column not filled by solid matter (or the void volume). Static porosity may be calculated from:

$P R-S=1-\frac{B D}{P D}$

where $B D$ is the rock bulk density, and $P D$ is the rock particle density. (see "Porosity" J. A. Vomocil. 1965. In Methods of Soil Analys is, ed. C. A. Black, Agronomy No. 9, pp. 299-314, American Soc iety of Agronomy, Inc., Madison, WI.)

$P R-D=$ dynamic, effective or hydrodynamic porosity $\left(\mathrm{cm}^{3} / \mathrm{cm}^{3}\right)$. This is the actual porosity available for fluid transport in the column (less than or equal to PR-S). Usually, a non-sorbing species is added to the ground water influent to determine the dynamic porosity. Figures $\mathrm{C} 1$ and $\mathrm{C} 2$ show a tritium breakthrough curve for two flow rates in the same column, from which the dynamic porosity and dynamic pore volume (below) can be calculated.

$C V O L=$ column volume $=L D^{2} / 4\left(\mathrm{~cm}^{3}\right)$.

PVOLS $=$ static pore volume $=(P R-S)(C V O L)\left(\mathrm{cm}^{3}\right)$.

$Q=$ flow rate through the column $\left(\mathrm{cm}^{3} / \mathrm{yr}\right)$.

PV-S = pore water or darcy velocity $(M / y r)$ calculated from the static porosity:

$P V-S=L Q /(P R-S)$. 


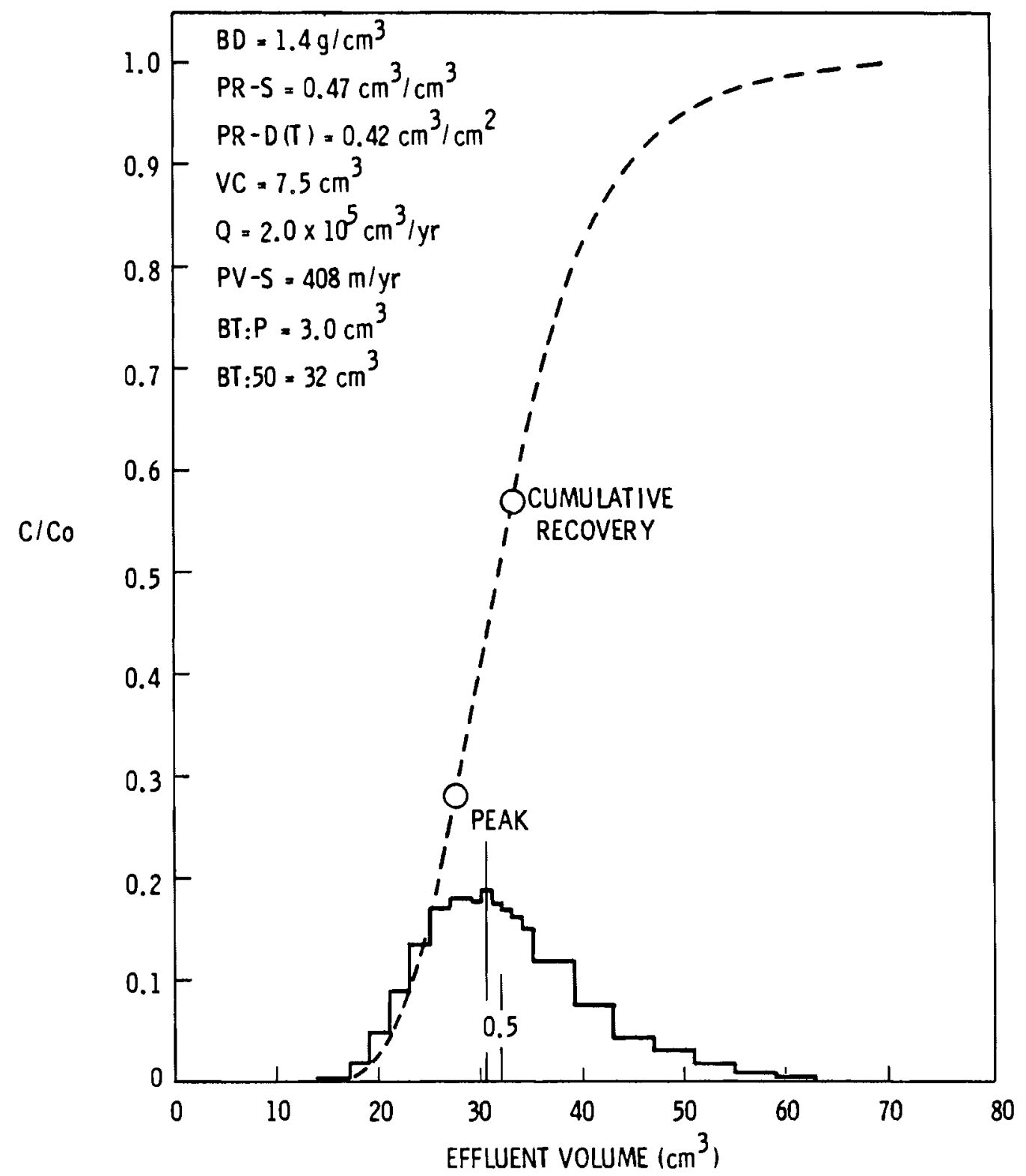

FIGURE C.1. Tritium Breakthrough Curve for $\mathrm{C} / \mathrm{Co}$ with Flow Rate of $0.388 \mathrm{ml} / \mathrm{min}$ 


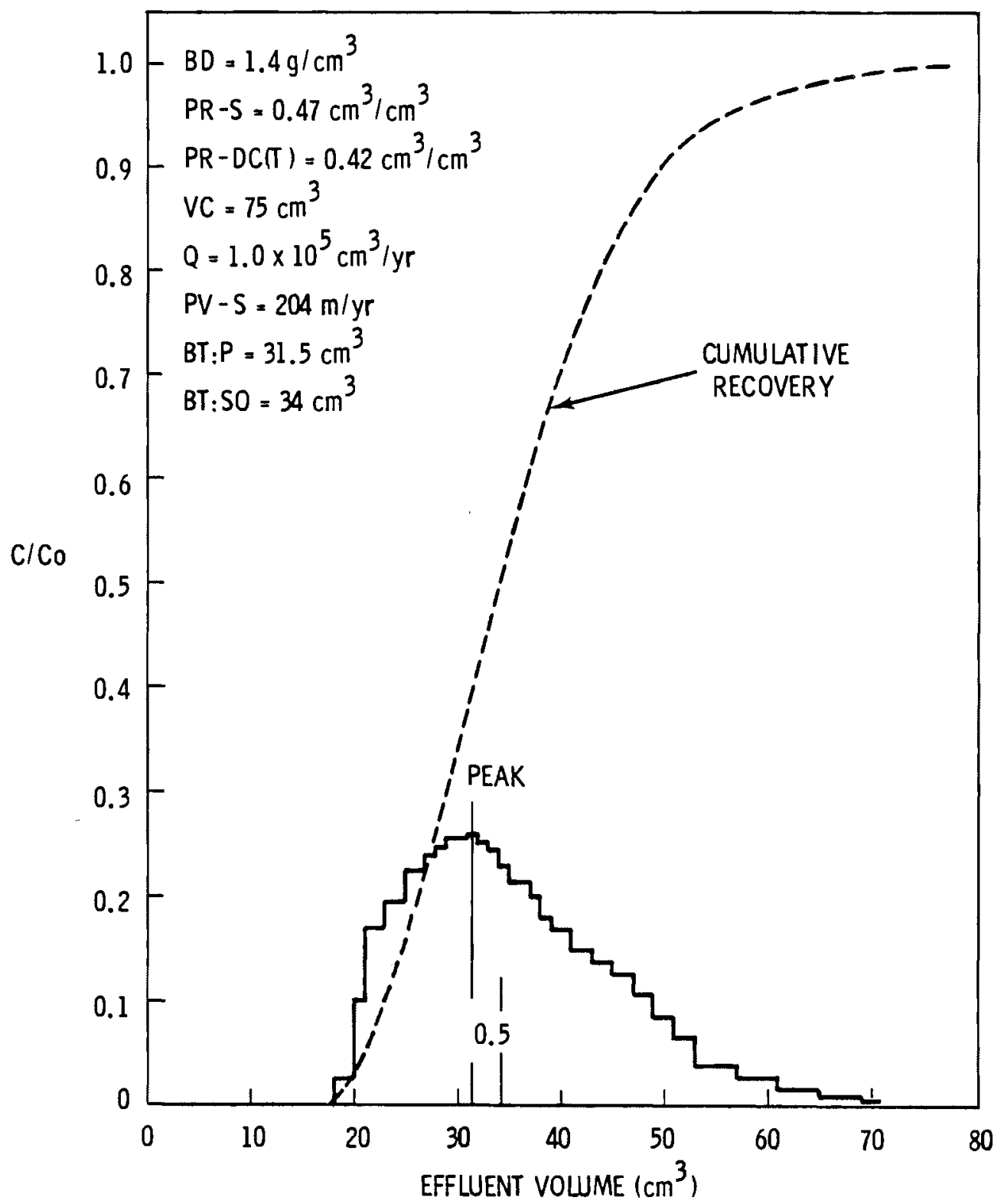

FIGURE C.2. Tritium Breakthrough Curve for C/Co with Flow Rate of $0.194 \mathrm{ml} / \mathrm{min}$ 
This is the linear velocity of the liquid moving through the column, assuming that the entire void space, PVOLS, is available for transport. $P V-D=$ pore water velocity $(M / y r)$ relative to the dynamic pore volume: $P V-D=L Q /(P R-D)$.

$Q T=$ total effluent $\left(\mathrm{cm}^{3}\right)$ collected in the experiment from its beginning to time $=T$ at the end of the experiment.

$B T: P=$ breakthrough volume for a spike/peak injection of radionuclide tracer. This is the volume element in which the maximum or peak tracer effluent concentration is observed.

BT:50 = breakthrough volume for $50 \%$ recovery of the initial spike or for $C / C_{0}=0.50$ for a column-loading experiment $(C=$ concentration of tracer in the effluent, $C_{0}=$ tracer concentration in the influent).

For ideal chromatographic behavior, a spike injection should yield a gaussian peak in the effluent tracer concentration vs. effluent volume curve. Figures $\mathrm{C} 1$ and $\mathrm{C} 2$ demonstrate $\mathrm{BT}: \mathrm{P}$ and $\mathrm{BT}: 50$ for tritium in a column of crushed Westerly granite. The particle density is about $2.6 \mathrm{~g} / \mathrm{cm}^{3}$ and the bulk density is $1.4 \mathrm{~g} / \mathrm{cm}^{3}$. The static porosity is given by Eq. (C1):

$$
P R-S=1-\frac{1.4}{2.6}=0.46
$$

The column volume is roughly $\mathrm{CVOL}=75 \mathrm{~cm}^{3}$ which gives:

$$
\begin{aligned}
\text { PVOLS } & =(P R-S) \text { (CVOL) } \\
& =34 \mathrm{~cm}^{3} .
\end{aligned}
$$

If tritrium were an adsorbed species, it would be retarded relative to the ground water, and the breakthrough (BT:P and BT:50) would be found at volumes in excess of $34 \mathrm{ml}$ of effluent. Two conclusions may be made from the figures:

1. The behavior of tritium in a column of crushed Westerly granite (20-50 mesh) does not follow ideal chromatographic behavior.

2. The effective or dynamic porosity for tritium in a column of crushed granite is less than the static porosity. The ground water does not flow equally through the entire void volume of the column. 
It is an established fact that tritium of ten exchanges iostopically with natural hydrogen and in columns with 1 arge surface areas can be retarded relative to ground water. Non-sorbing anions such as $\mathrm{Cl}^{-}$are subject to anion exclusion from negatively charged surfaces and may break through in less than one static pore volume. Anions may also be retarded relative to ground water if there are enough positively charged surfaces (anion exchange capacity) present. Methods used to determine a dynamic pore volume should be stated explicitly when reporting data from dynamic retardation experiments.

From a safety assessment viewpoint, conservative retardation factors are those values that yield a lower limit for the arrival of a radionuclide (e.g. a maximum transport velocity). For this reason the static porosity should be used for pore volume calculation. This, however, yields a retardation factor for tritium of less than one in the two figures shown. Safety-assessment modelers and researchers must jointly decide whether to measure retardation factors using the static pore volume (which will result in conservative values) or a dynamic pore volume. Reported column data should include both parameters so that future interpretation can be made on either basis.

Assuming that the concept of pore volume is resolved, a retardation factor is calculated from:

$$
R F=V_{w} / V_{n}
$$

where $V_{W}=$ velocity of the ground water and $V_{n}=$ velocity of the radionuclide. The relationship between a retardation factor and the breakthrough point for a radionuclide is:

$$
R F=\frac{B T: 50}{\text { PVOL }}
$$

or

$$
R F=\frac{B T: P}{P V O L}
$$

To obtain a conservative number for RF, the lesser number for $B T: 50$ or $B T: P$ should be used. 
To calculate a Kd value from a retardation factor, or vice versa, the following relationship is used:

$$
R F=1+\frac{(B D)(K d)}{P R-S}
$$

(assuming the static porosity PR-S is appropriate).

If the radionuclide used in a retardation experiment is highly adsorbed, years may be required to elute the tracer spike. However, if the radionuclide distribution can be determined within the column or core, a retardation factor can be calculated.

For a tracer spike injection, a peak distribution should be obtained within the column. The ceter of mass of the peak is the average distance $X$ traveled by the peak.

The distance traveled by the water in the same time is given by (QT)(L)/(PVOLS). The retardation factor is the ratio of the distance traveled by ground water to the average radionuclide migration distance in time $T$ :

$$
R F=\frac{(Q T)(L)}{(X)(P V O L S)}
$$




\section{DISTRIBUTION}

No. of

Copies

OFFSITE

A. A. Churm

DOE Patent Division

9800 South Cass Avenue

Argonne, IL 60439

27 DOE Technical Information Center

2 Argonne National Laboratory

Reference Library

9800 South Cass Avenue

Argonne, IL 60439

Battelle Memorial Institute

Office of Nuclear Waste Isolation

Attn: Bever ly Rawles

505 King Avenue

Columbus, $\mathrm{OH} 43201$

2 Brookhaven National Laboratory

Reference Section

Information Division

Upton, Long Island, NY 11973

20 Wayne A. Carbiener

Office of Nuclear Waste Isolation

Battelle Memorial Institute

505 King Avenue

Columbus, $\mathrm{OH} \quad 43201$

Carl R. Cooley

DOE Office of Waste Management

Washington, DC 20545

Jared Davis

27 Nuclear Regulatory

Commission

Washington, DC 20555
No. of

Copies

Environmental Protection Agency

Office of Radiation Programs

Technical Assessment Division Aw559

Washington, DC 20460

Colin A. Heath

DOE Division of Waste Management

Washington, DC 20545

William M. Hewitt

Office of Nuclear Waste Isolation

Battelle Memorial Institute

505 King Avenue

Columbus, $\mathrm{OH} 43201$

Muzaffer Kehnemuyi

Office of Nuclear Waste Isolation

Battelle Memorial Institute

505 King Avenue

Columbus, $\mathrm{OH} 43201$

John F. Kircher

Office of Nuclear Waste I solation

Battelle Memorial Institute

$505 \mathrm{King}$ Avenue

Columbus, $\mathrm{OH} 43201$

2 Lawrence Berkeley Laboratory

Reference Library

University of California

Berkeley, CA 94720

2 Lawrence Livermore Laboratory

Reference Library

P.0. Box 808

Livermore, CA 94550 
No. of

Copies

2 Los Alamos Scientific Laboratory

Reference Library

P.0. Box 1663

Los Alamos, NM 87544

John T. McGinn is

Office of Nuclear Waste I solation

Battelle Memorial Institute

505 King Avenue

Columbus, $\mathrm{OH} 43201$

2 Savannah River Laboratory

Reference Library

Aiken, SC 29801

She ldon Meyers

DOE Office of Nuclear Waste Management

Washington, DC 20545

2 Barry Naft

NUS Corporation

4 Research Place

Rockville, MD 20805

J. 0. Neff

Department of Energy

Columbus Program Office

505 King Avenue

Columbus, $\mathrm{OH} 43201$

2 Neil A. Norman

Environmental Sciences

Department

Bechtel National Inc.

P.0. Box 3965

San Francisco, CA 94105

2 Oak Ridge National Laboratory

Central Research Library

Document Reference Section

Oak Ridge, TN 37830

Howard P. Stephens

Sandia Laboratories

P.0. Box 5800

Albuquerque, NM 87115
No. of

Copies

David B. Stewart

U.S. Geological Survey

National Center 959

Reston, VA 22092

Larry Benson

Lawrence Berkeley Laboratory

1 Cyclotron Road

Bldg 70A/1160

Berkeley, CA 94720

Ernest Bondietti

Oak Ridge National Laboratory

Bldg 3504

P.0. Box $X$

Oak Ridge, TN 37830

H. Clyde Clairborne

Oak Ridge National Laboratory

Bldg 3017

P.0. Box $X$

Oak Ridge, TN 37830

Jess M. Cleveland

Chief, Transuranium Research Project

USGS

Water Resources Division

Box 25046

Denver Federal Center

Lakewood, CO 80225

David G. Coles

Lawrence Livermore Laboratory

University of California

P.0. Box 808

Livermore, CA 94550

Peter Columbo

Brookhaven National Laboratory

Dept. of Applied Science

Upton, New York 11933

George A. Cowan

LoS Alamos Scientific Laboratory

P.0. Box 1163

Los Alamos, NM 87545 
No. of

Copies

Robert G. Dosch

Sandia Laboratories

P.0. Box 5800

Albuquerque, NM 87115

Geoffrey Eichholz

Regent's Professor of Nuclear Engineering

School of Nuclear Engineering

Georgia Institute of Technology

Atlanta, GA 30332

Bruce R. Erdal

Los Alamos Scientific Laboratory

CNC-11, MS-514

Los Alamos, NM 87545

Sherman Fried

Argonne National Laboratory

9700 S. Cass Avenue

Argonne, IL 60439

Norman Hubbard

Office of Nuclear Waste

Isolation

505 King Avenue

Columbus, Ohio 43201

Dana Isherwood

Lawrence Livermore Laboratory

MS L-224

P.0. Box 808

Livermore, CA 94550

George Al. Kolstad

DOE Division of Energy Research

Washington, DC 20545

Kurt Kraus

110 Ogontz Lane

Oak Ridge, TN 37830

Daniel T. Lam

Materials Science

Bldg. 212

Argonne National Laboratory

$4700 \mathrm{~S}$. Cass Avenue

Argonne, Illino is 60437
No. of

Copies

Harry Landon

NRC, Research Division

Washington, DC 20555

Paul W. Levy

Brookhaven National Laboratory

Physics Department

Upton, L.I., NY 11973

Stan E. Logan

Nuclear Waste Management Program Los Alamos Technical Associates, Inc.

P.0. Box 410

Los Alamos, NM 87554

I. Wendell Marine

E. I. du Pont de Nemours Co.

Savannah river Laboratory

Aiken, SC 29081

Robert E. Meyer

Oak Ridge National Laboratory

P.0. Box X

Oak ridge, TN 37830

Ivars Neretnieks

University of California

Lawrence Berkeley Laboratory

Earth Sciences Bldg. 90

1 Cyclotron Road

Berkeley, California 94720

Edward Nornis

Los Alamos Scientific Laboratory

P.0. Box 1663

Los Alamos, NM 87545

Paul Rickert

Argonne National Laboratory

9700 South Cass Avenue

Argonne, IL 60439

Barry E. Scheetz

Penn State University

Materials Research Laboratory

Room 223

University Park, PA 16802 
No. of

Copies

Martin Seitz

Argonne National Laboratory

9700 S. Cass Avenue

Argonne, IL 60439

Robert 3. Silva

Lawrence Berkeley Laboratory

1 Cyclotron Road

Bldg. 70A/1160

Berkeley, California 94720

Victor Swan

Washington State University

Geo logy Department

Pullman, WA 99163

John Tewhey

Lawrence Berkeley Laboratory

$L-205$

P.0. Box 808

Livermore, CA 94550

Rosemary Vidale

Los Alamos Scientific Laboratory

P.0. Box 1663

Los Alamos, NM 87545

Barry G. Wahlig

School of Nuclear Engineering Georgia Institute of Technology

Atlanta, GA 30332

Robert L. Watters

DOE Division of Biomedical and

Environmental Research

Washington, DC 20545

Allen Weiss

Brookhaven National Laboratory

Bldg 830

Upton, L.I., NY 11973

\section{FOREIGN}

Bundesministerium fur Forschung und Technologie

Stressemannstrasse 2

D-5300 Bonn

F.R. Of GERMANY
No. of

Copies

Ferruccio Gera

Radiation Protection and

Waste Management Division

Nuclear Energy Agency/OECD

38 boulevard Suchet

75016 Paris

FRANCE

2 INIS Clearinghouse

International Atomic Energy Agency

P.0. Box 590

A-1011, Vienna

AUSTRIA

Library

Studsvik Energiteknik $A B$

S-611 01 Nykoping

SWEDEN

F. P. Sargent

Atomic Energy of Canada Limited

Whiteshell Nuclear Research

Establishment

Pinawa, Manitoba

Canada ROE 1 LQ

Egbert Schapermeier

Battelle-Institute e.V.

Am Romerhof 35

D-6000 Frankfurt am Main 90

$F . R$. of GERMANY

Dr. Les Dole

c/o Dr. Klaus Kuhn

Institut fur Tiefiagerung

Wissenschaftliche Abteilung

Berliner Strasse 2

D-3392 Clausthal - Zellerfeld

West Germany (FRG)

Robert Gillham

Department of Earth Sciences

University of Water 100

Water 100 , Ontario

CANADA 
No. of

Copies

David Grey

Institute of Geologic Sciences

Exhibition Road

$S$. Kensington

London, SW7-2DE

UNITED KINGDOM

Alex T. Jakubick

Nuclear Research Center

$7500 \mathrm{Kar}$ lsruhe

P.0. 3640

FEDERAL REPUBLIC OF GERMANY

Tjalle Vandergraff

Atomic Energy of Canada Limited

Whiteshell Nuclear Research

Establishment

Pinawa, Manitoba

CANADA ROE 1 LO

\section{ONSITE}

6 DOE Richland Operations Office

0. J. Elgert

R. B. Goranson

H. E. Ransom

J. J. Schreiber

D. J. Squires

F. R. Standerfer
No. of

Copies

8 Rockwell Hanford Operations

R. C. Arnett

G. S. Barney

R. A. Deju

M. R. Fox

G. S. Hunt

M. J. Smith

W. W. Schulz

Rockwell Document Control

60 Pacific Northwest Laboratory

L. L. Ames

D. Bradley

A. Brandstetter

D. B. Cear lock

C. R. Cole

D. J. Bradley

M. R. Kreiter

W. L. Kuhn

R. W. Nelson

C. A. Novich

A. M. Platt

D. Rai (5)

J. F. Relyea (5)

R. J. Serne (5)

J. W. Shade

R. G. Strickert

Technical Information Library (5)

Publishing Coordination (Sh)(2) Water and Land Resources

Department Library (25) 
